A N N A L E S Annales de Bretagne et des Pays de l'Ouest

Anjou. Maine. Poitou-Charente. Touraine

123-4 | 2016

Varia

\title{
Sede vacante
}

Les périodes interépiscopales dans les diocèses de Tréguier, Saint-Brieuc et Saint-Malo aux XVII ${ }^{\mathrm{e}}$ et XVIII ${ }^{\mathrm{e}}$ siècles

Sede vacante. Interepiscopal periods in the dioceses of Tréguier, Saint Brieuc and Saint Malo in the 17th and 18th centuries

\section{Olivier Charles}

\section{(Q) OpenEdition}

\section{Journals}

Édition électronique

URL : http://journals.openedition.org/abpo/3433

DOI : $10.4000 / a b p o .3433$

ISBN : 978-2-7535-5365-1

ISSN : 2108-6443

Éditeur

Presses universitaires de Rennes

Édition imprimée

Date de publication : 30 décembre 2016

Pagination : $93-120$

ISBN : 978-2-7535-5363-7

ISSN : 0399-0826

Référence électronique

Olivier Charles, "Sede vacante », Annales de Bretagne et des Pays de l'Ouest [En ligne], 123-4 | 2016, mis en ligne le 30 décembre 2018, consulté le 03 janvier 2020. URL : http://journals.openedition.org/abpo/ 3433 ; DOI : 10.4000/abpo.3433 


\title{
Sede vacante
}

\section{Les périodes interépiscopales dans les diocèses de Tréguier, Saint-Brieuc et Saint-Malo aux XVII ${ }^{\mathrm{e}}$ et XVIII ${ }^{\mathrm{e}}$ siècles}

\author{
Olivier CHARLES \\ Chercheur associé, CERHIO-UMR 6258 - Université de Rennes 2
}

Les curies épiscopales de l'époque moderne en Bretagne n'ont pour l'heure guère retenu l'attention des historiens ${ }^{1}$. L'étude de Frédéric Meyer sur La Maison de l'évêque dans un large sud-est du royaume de France ${ }^{2}$ est en la matière cruelle et révèle l'ampleur d'un chantier qu'un très ancien article isolé du chanoine Luco consacré au diocèse de Vannes ne saurait dissimuler ${ }^{3}$. En particulier, l'action des auxiliaires précieux des prélats que sont les vicaires généraux - d'ailleurs encore inconnus pour nombre d'entre eux - est peu étudiée ${ }^{4}$, même si quelques travaux, souvent inédits, laissent

1. Ce que constatait déjà Jean Quéniart il y a une trentaine d'années (QUÉNIART, Jean, "Bulletin historique : l'histoire religieuse de la Bretagne à l'époque moderne (XVI'-XVIII siècles) ", Mémoires de la Société d'histoire et d'archéologie de Bretagne, t. XIII, 1986, p. 267).

2. MeYER, Frédéric, La Maison de l'évêque. Familles et curies épiscopales entre Alpes et Rhône (Savoie-Bugey-Lyonnais-Dauphiné-Comtat Venaissin) de la fin du XVI à la fin du XVIII ${ }^{e}$ siècle, Paris, Honoré-Champion, 2008, 621 p.

3. Luco, Jean-François, "Organisation de l'ancien personnel ecclésiastique du diocèse ", Bulletin de la Société polymathique du Morbihan, 1874, p. 41-60. Signalons aussi, dans un travail ancien mais toujours très précieux, les listes des personnels des curies de Dol, Rennes et Saint-Malo, proposées par GuILlotin De CoRson, Amédée, Pouillé historique de l'archevêché de Rennes, Rennes, Fougeray/Haton, t. I, 1880, 808 p.

4. Valable à l'échelle de la province, le constat l'est également largement à celle du royaume : CHÂTELLIER, Louis, " Une enquête à ouvrir : les collaborateurs directs de l'évêque (suffragants et vicaires généraux) dans l'Europe des XVI ${ }^{\mathrm{e}}$-XVII ${ }^{\mathrm{e}}$ siècles ", dans CHAIX, Gérald (dir.), Le diocèse. Espaces, représentations, pouvoirs. France, $X V^{e}-X X^{e}$ siècle, Paris, Cerf, 2002, p. 179-198; MEYER, Frédéric, "Vicaires généraux et administrations diocésaines en France et en Italie à la fin du XVIII e siècle ", dans MEYER, Frédéric, MiLBACH, Sylvain (textes réunis par), Les échanges religieux entre l'Italie et la France, 1760-1850. Regards croisés, Sociétés, Religions, Politiques, $n^{\circ} 15$, Université de Savoie, 2010, p. 27-42. S'agissant de la Bretagne, on dispose de trois portraits : FRELAUT, Bertrand, « Un portrait inconnu d'un vicaire général de Dol, Jean-Baptiste Drillet de Pénamprat (1728-1788) ", Mémoires de la Société d'histoire et d'archéologie de Bretagne, t. XXIX, 2001, p. 103-106; Tudo, Michèle et Joseph, « Notice sur 
entrevoir l'importance de tel ou tel dans la mise en œuvre des politiques de réforme et l'administration des diocèses ${ }^{5}$.

À cet égard, les périodes interépiscopales, c'est-à-dire les séquences chronologiques de transition entre deux épiscopats, qui ne coïncident qu'imparfaitement avec la régale, semblent être des observatoires intéressants pour saisir le passage d'une administration épiscopale à une autre, d'autant qu'intervient un autre acteur : le chapitre cathédral. Ces périodes sont en effet le moment où les chapitres, subordonnés aux évêques par le concile de Trente ${ }^{6}$, relèvent la tête et administrent directement les diocèses. Rarement évoquées ${ }^{7}$, elles se situent au croisement de deux historiographies aujourd'hui fécondes : l'une récemment renouvelée, celle des chapitres ${ }^{8}$; l'autre faisant l'objet de nouveaux questionnements, celle des évêques ${ }^{9}$. Il n'est donc pas certain que l'on puisse se contenter de considérer que « l'absentéisme, souvent total au XVI ${ }^{\mathrm{e}}$ siècle, l'absentéisme partiel obligé des évêques-politiques, les longues vacances de certains interrègnes [...], les valses-hésitations qui font qu'entre la nomination, le sacre et l'entrée effective dans le diocèse, il

Jean-Gabriel Le Gofvry, vicaire général du diocèse de Saint-Brieuc (1724-1796) ", Mémoires de la Société d'émulation des Côtes-d'Armor, t. CXXXI, 2003, p. 113-132; MonNIER, Marcel, « Le parcours de Jean Lemarié, chanoine de la cathédrale Saint-Vincent de Saint-Malo (15771638) ", Bulletin et mémoires de la Société archéologique d'Ille-et-Vilaine, t. CXI, 2007, p. 27-53.

5. Voir en particulier : RESTIF, Bruno, La Révolution des paroisses. Culture paroissiale et Réforme catholique en Haute-Bretagne aux XVe et XVIT siècles, Rennes, PUR, 2006, p. 93, 100-101, 130 et 133-134; PÉRENNEC, Ronan, L'épiscopat de Mgr de La Bourdonnaye, évêque et comte de Léon (1702-1745), mémoire de maîtrise (Fanch Roudaut, dir.), université de Bretagne occidentale, 1986, p. 14-16; BRAY, Isabelle, La vie religieuse dans le diocèse de Cornouaille sous les épiscopats de monseigneur de Ploeuc du Tymeur et monseigneur Farcy de Cuillé, mémoire de mâ̂trise (Fanch Roudaut, dir.), université de Bretagne occidentale, 1987, p. 20-21 et 260-274; PÉRÈS, Georges Henri, La réforme du clergé séculier dans le diocèse de Vannes d'après le Catalogue de 1654, mémoire de master 2 (Georges Provost, dir.), université Rennes 2, 2011, p. 34-39 et JAFFRÉNOU, Andreï, Le clergé de Haute-Cornouaille à la fin de l'Ancien Régime, mémoire de master 2 (Georges Provost, dir.), université Rennes 2, 2014, t. I, p. 282-286 et t. II, annexe 47.

6. Ce qui ne signifie pas nécessairement soumission et passivité des chapitres comme le montrent bien MinoIs, Georges, La Bretagne des prêtres dans le Trégor d'Ancien Régime, Spézet, Beltan, 1987, p. 99-109 ou CHARLES, Olivier, "Quand un évêque visite son chapitre... Le chapitre cathédral de Saint-Malo au début du XVIII ${ }^{\mathrm{e}}$ siècle : un corps à réformer? ", Mémoires de la Société d'histoire et d'archéologie de Bretagne, t. LXXXIX, 2011, p. 59-79.

7. Le chanoine manceau Nepveu de La Manouillère dépeint précisément l'une de ces périodes entre janvier et juillet 1778, preuve s'il en est de l'importance que revêt cette transition pour lui et sa compagnie, dans Granger, Sylvie, HuBERT, Benoît, TARONI, Martine (éd.), Journal d'un chanoine du Mans. Nepveu de La Manouillère (1759-1807), Rennes, PUR, 2013, p. 302-313. Pour la période médiévale, on pourra consulter LE BLÉVEC, Daniel, "Sede vacante. Administrer l'évêché à la mort de l'évêque. Viviers, juin 1382 ", dans BARRALIS, Christine, BoudET, Jean-Patrice, DELIVRÉ, Fabrice, GENET, Jean-Philippe (dir.), Église et État, Église ou État? Les clercs et la genèse de l'État moderne, Paris, Publications de la Sorbonne, 2014, p. 215-224.

8. Dans le sillage de LoupÈs, Philippe, Chapitres et chanoines de Guyenne aux XVII et XVIII ${ }^{e}$ siècles, Paris, Éditions de l'École des Hautes Études en Sciences Sociales, 1985, 590 p. S'agissant de la Bretagne, je me permets de renvoyer à CHARLES, Olivier, Chanoines de Bretagne. Carrières et cultures d'une élite cléricale au siècle des Lumières, Rennes, PUR, 2004, 456 p.

9. Voir par exemple Gomis, Stéphane (dir.), Les évêques des Lumières : administrateurs, pasteurs et prédicateurs, Clermont-Ferrand, Presses universitaires Blaise-Pascal, 2015, 162 p. 
s'écoule, même au XVIII ${ }^{\mathrm{e}}$ siècle, souvent beaucoup de temps, rendent nécessaire l'emploi de subterfuges : désignation d'un coadjuteur, et surtout remplacement de l'évêque par des vicaires généraux, ou, comme à Nantes, par des $\operatorname{archidiacres}^{10}$ ». Outre que la spécificité des périodes de transition est alors ignorée, la qualité des administrateurs est quant à elle passée sous silence. En effet, pendant une période plus ou moins longue, des vicaires capitulaires - et non des vicaires généraux ou des grands vicaires, même si les sources font souvent l'amalgame - et une officialité nommés par le chapitre président aux destinées du diocèse

La chronologie est immuable. Après le départ de l'évêque, qu'il s'agisse d'un décès ou d'un transfert, son administration est démise de ses fonctions. Le chapitre cathédral déclare alors prendre les rênes du diocèse jusqu'à l'arrivée d'un nouveau prélat. La prise de possession de ce dernier se traduit par le renvoi immédiat du personnel capitulaire et l'installation d'une nouvelle administration. Pendant ces phases de transition, au-delà de l'identification d'une certaine élite ecclésiastique, celle des administrateurs diocésains de haut niveau, il semble possible de juger de la ligne de conduite des évêques nouvellement installés. Font-ils preuve de pragmatisme en reconduisant le personnel ancien ou nomment-il des collaborateurs de confiance, éventuellement extérieurs à leur nouveau diocèse? Peut-on repérer une pratique constante, des évolutions ou alors chaque installation est-elle un cas d'espèce? L'insertion du chapitre dans ce jeu mérite elle aussi d'être interrogée. Se fondant sur une lecture fine des trois temps de la vacance épiscopale, l'étude de trois diocèses du nord de la Bretagne, ceux de Tréguier, SaintBrieuc et Saint-Malo, entre le concile de Trente et la Révolution ${ }^{11}$, permet d'ouvrir le dossier et d'esquisser des réponses à ces questions ${ }^{12}$.

\section{La fin d'un épiscopat}

Un décès, une résignation ou un transfert vers un autre siège mettent fin à un épiscopat ${ }^{13}$. La plupart des évêques du corpus - trente sur qua-

10. Devallly, Guy (dir.), Histoire religieuse de la Bretagne, Chambray, CLD, 1980, p. 131-132.

11. Cette réflexion associe ainsi deux diocèses déjà bien étudiés - Saint-Malo (RESTIF, Bruno, La Révolution des paroisses..., op. cit.) et Tréguier (Minois, Georges, Un échec de la Réforme catholique en Basse-Bretagne : le Trégor du XVI siècle au XVIII siècle, thèse dactylographiée (Jean Delumeau, dir.), université Rennes 2, 1984, 4 volumes, 1044 p.) et un autre encore bien mal connu - Saint-Brieuc (pour lequel il convient de consulter PROVOST, Georges, "Les "fastes de l'Église briochine" : Ruffelet et la construction d'une identité diocésaine ", dans ChaRles, Olivier (dir.), Christophe Michel Ruffelet, Les Annales briochines (1771). Saint-Brieuc : histoire d'une ville et d'un diocèse, Rennes, Presses universitaires de Rennes, 2013, p. 97-121).

12. Précisons que pour le sud de la province, LE MENE, Joseph Marie, Histoire du diocèse de Vannes, Vannes, Lafolye, 1889, t. 2, 555 p. offre de très intéressants développements sur les transitions.

13. Pour des présentations solides des évêques bretons, se reporter à : POCQUET DU HAuT-Jussé, Barthélemy Amédée, "Les évêques de Bretagne dans la Renaissance religieuse du XVII e siècle ", Annales de Bretagne, t. 54, 1947, p. 30-59; MeYER, Jean, "La vie 
rante-neuf - meurent en charge. Les transferts concernent, quant à eux, surtout - huit sur quatorze - des Trégorrois et des Briochins du XVIII ${ }^{\mathrm{e}}$ siècle $^{14}$. À cette époque, ces évêchés s'apparentent en effet à des étapes dans des carrières ${ }^{15}$ que l'on souhaite plus brillantes et plus lucratives. Ceci n'est évidemment pas sans incidence sur la résidence des prélats. Ainsi, à Tréguier, entre 1761 et 1791, " entre les périodes de vacances, les séjours aux États, aux assemblées du clergé et à la cour, les absences pour affaires familiales, c'est plus d'une année sur deux que l'administration est confiée aux vicaires généraux ${ }^{16}$ ". À Saint-Brieuc, c'est, au même moment, le retour " aux prélats de cour trop souvent absents ${ }^{17}$ ". Saint-Malo, où se succèdent au cours du siècle plusieurs personnalités de grande qualité dominées par la figure de La Bastie ${ }^{18}$, se caractérise par un épiscopat très stable ${ }^{19}$. Ce diocèse a d'ailleurs été dirigé par des évêques dans l'ensemble consciencieux, dans le sillage de la grande entreprise réformatrice menée par Guillaume Le Gouverneur entre 1611 et $1630^{20}$. À Saint-Brieuc, la mise en œuvre des préceptes tridentins a été pour l'essentiel l'œuvre de quatre évêques Melchior de Marconnay, André Le Porc de La Porte, Étienne de Villazel et Denis de La Barde ${ }^{21}$ - entre 1602 et 1675 , pendant qu'à Tréguier elle est dominée par les figures de Guy Champion de Cicé (1620-1635), de Balthazar Grangier (1646-1679) puis, plus tard, de François de La Fruglaie de Kerver (1732-1745) ${ }^{22}$. Partout, l'action réformatrice - certainement amorcée dès avant Trente - avait été retardée par les guerres de la Ligue ${ }^{23}$.

À cette époque comme à la veille de la Révolution, l'organisation des obsèques du prélat défunt revient au chapitre, conformément au

religieuse en Bretagne à l'époque moderne ", dans DevalLly, Guy (dir.), Histoire religieuse de la Bretagne..., op. cit., p. 127-135; ChÉDEville, André, Provost, Georges, "Évêques ", dans CASSARD, Jean-Christophe, CROIX, Alain, LE QuÉAU, Jean-René, VEILLARD, Jean-Yves (dir.), Dictionnaire d'histoire de Bretagne, Morlaix, Skol Vreizh, 2008, p. 278-279.

14. L'annexe 1 présente l'ensemble des épiscopats des trois diocèses. Les données rassemblées permettent de bien baliser les périodes de transition.

15. S'agissant des carrières, seuls trois évêques (sur 21) à Tréguier, un à Saint-Brieuc (sur quatorze) et à Saint-Malo (sur quatorze), sont originaires de leur diocèse.

16. MinoIs, Georges, La Bretagne des prêtres..., op. cit., p. 242.

17. NiÈres, Claude (dir.), Histoire de Saint-Brieuc et du pays briochin, Toulouse, Privat, 1991, p. 74. Cela étant, seule une étude fine des registres d'insinuations ecclésiastiques permettra de préciser le nombre et la durée des séjours des évêques hors de la cité épiscopale.

18. BeRTHELOT DU ChESNAY, Charles, Les prêtres séculiers en Haute-Bretagne au XVIIf siècle, Rennes, Presses universitaires de Rennes, 1984, p. 639.

19. Quatre évêques nommés au cours du siècle contre sept à Saint-Brieuc et à Tréguier.

20. Restif, Bruno, La Révolution des paroisses..., op. cit., p. 125.

21. NiÈRES, Claude (dir.), Histoire de Saint-Brieuc..., op. cit., p. 64.

22. MinoIs, Georges, La Bretagne des prêtres..., op. cit., p. 100-109, 240-241.

23. Restif, Bruno, La Révolution des paroisses..., op. cit., p. 118-119 et, pour l'examen de la position des évêques pendant les événements, LE Goff, Hervé, La Ligue en Bretagne. Guerre civile et conflit international (1588-1598), Rennes, PUR, 2010, p. 110-121 notamment, ainsi que LAFAYE, Elsa, "La religion fut le prétexte? "le rôle des évêques dans les guerres de la Ligue en Bretagne de 1588 à 1598, mémoire de master 2 (Ph. Hamon, dir.), université Rennes 2, 2007, 251 p. 
Cérémonial romain en vigueur dès les premières décennies du XVII ${ }^{\mathrm{e}}$ siècle $^{24}$, comme le rappellent d'ailleurs les chanoines briochins à l'occasion de la disparition de Denis de La Barde ${ }^{25}$. La cérémonie se déroule en général deux ou trois jours après le décès, sauf situation exceptionnelle dont relève la mort de Frétat de Boissieu en 1720. En effet, l'évêque de Saint-Brieuc décède le 30 octobre à Ancenis à la fin des États de Bretagne auxquels il participait mais un incident oblige le convoi qui ramène la dépouille à séjourner à Rennes : il n'arrivera à Saint-Brieuc que le 6 ou 7 novembre ${ }^{26}$. De même, c'est avec surprise que les chanoines de Saint-Malo apprennent la mort subite d'Antoine Joseph des Laurents à l'entrée de la ville alors qu'il rentre de l'Assemblée générale du clergé le 15 octobre 1785. Afin d'établir les circonstances du décès - un accident cérébral -, un chanoine assiste alors à " l'ouverture de son corps " qui se déroule le 16 au soir au palais épiscopal avant toute forme de cérémonie ${ }^{27}$. En règle générale, lorsque la fin est imminente, le chapitre prend ses dispositions pour assurer une bonne mort au prélat. Ainsi, à Tréguier, La Fruglaye, comme tous les autres évêques, meurt " après avoir reçu le Saint viatique qui lui fut porté par M. le chantre accompagné de tout le clergé du haut et bas chœur et le même jour à 9 heures du soir il reçut l'extrême-onction par les mains de mond. sieur le chantre $^{28}$ ". Ensuite, les chanoines se rendent " en corps et avec leurs habits au manoir épiscopal faire aspersion d'eau bénite ${ }^{29}$ " sur le corps du défunt, après avoir fait chanter un Nocturne. Après le décès de Champion de Cicé, le chapitre avait fait " sonner les cloches lentement " puis était retourné au manoir épiscopal après complies pour chanter le De profundis ${ }^{30}$. Le chapitre ordonne ensuite la célébration pendant huit jours d'une messe solennelle à la mémoire de l'ancien évêque. Mais l'agonie est parfois longue. Ainsi, c'est deux semaines avant le décès de Denis de La Barde que quatre chanoines

24. Bréviaires, rituels, missels, cérémonials romains sont vraisemblablement adoptés dès les épiscopats d'André Le Porc de La Porte à Saint-Brieuc, Guillaume Le Gouverneur à Saint-Malo et Guy Champion de Cicé à Tréguier, dans ce dernier cas au prix d'un sévère affrontement avec le chapitre. Voir respectivement : CHARLES, Olivier (dir.), Christophe Michel Ruffelet, Les Annales briochines, 1771..., op. cit., p. 280; RESTIF, Bruno, La Révolution des paroisses..., op. cit., p. 203; Minors, Georges, "Réforme catholique et liturgie en Bretagne aux XVII ${ }^{\mathrm{e}}$ et XVIII ${ }^{\mathrm{e}}$ siècles ", Annales de Bretagne et des Pays de l'Ouest, t. 89, 1982, p. 454 et $459-461$.

25. Archives diocésaines (désormais Arch. dioc.) de Saint-Brieuc, 1 CH 2, délibération capitulaire du 24 mai 1675.

26. Sur cette anecdote, se reporter à CHARLEs, Olivier, Chanoines de Bretagne..., op. cit., p. 148.

27. «[...] où l'opération ayant été commencée par la tête, le sieur Métayer chirurgien juré de cette ville qui y présidait me fit observer que tous les vaisseaux qui rampent à la superficie du cerveau étaient engorgés, et qu'il y avait épanchement d'environ un verre de sang fort épais dans les fosses occipitales inférieures siège du cervelet, cause plus que suffisante de la fin du prélat... " (Arch. dép. d'Ille-et-Vilaine, 1 G 268, délibération capitulaire du 17 octobre 1785).

28. Arch. dép. des Côtes-d'Armor, 2 G 302, délibération capitulaire du 23 décembre 1745.

29. Arch. dép. des Côtes-d'Armor, 2 G 278, délibération capitulaire du 29 juillet 1616.

30. Arch. dép. des Côtes-d'Armor, 2 G 278, délibération capitulaire du 15 septembre 1635 . 
de la cathédrale de Saint-Brieuc se rendent à son chevet car, malade, il veut faire devant eux " profession de sa foi orthodoxe, catholique, apostolique et romaine ${ }^{31}$ ". À Tréguier, la santé de Balthazar Grangier décline à partir du 11 janvier 1679. Le 27, le chapitre décide de lui porter le viatique qu'il reçoit " avec beaucoup de dévotion et merveilleuse édification de tous les $\operatorname{assistants}^{32}$ ", honorant ainsi la dignité afférente à sa fonction. L'extrêmeonction lui est administrée le lendemain mais il ne mourra que le 2 février vers 22 heures 30 .

Le jour des obsèques, c'est un cérémonial connu de tous qui est suivi. Ainsi, à Saint-Brieuc, lors des obsèques de Denis de La Barde,

" l'on sortira de l'Église par la porte du bas de l'Église et la procession de la conduite du corps retournera dans l'Église en faisant à l'entour et entrera par la même porte, le corps sera déposé dans la nef et sous la chapelle ardente. Le clergé entrera au chœur et les religieux entre les deux ballustres, les dignités et chanoines laisseront les chaires des dignités et adjacents aux parents et assistants et le reste du clergé sera placé ensuite dans les chaires du chœur. À la fin de la messe le clergé sortira du chœur dans la nef pour assister aux cérémonies des cinq absolutions qui seront faites par le célébrant, lesdits Ruellan, Batas, David et Morand et pour porter le drap mortuaire lesdits de Labat, Bouan, Proffit et Nebout ${ }^{33}$ ".

Cette description lapidaire est heureusement éclairée par celle des obsèques de Balthazar Grangier à Tréguier en $1679^{34}$. On sait ainsi que pendant les quelques jours qui suivent son décès, l'évêché et la cathédrale sont plus que jamais les cœurs de la cité épiscopale où se règle le devenir du peuple des fidèles du diocèse, cours unis par les déplacements quotidiens du chapitre en corps. En effet, la compagnie officie sur les deux sites : à l'évêché, elle préside au transfert du corps embaumé de l'évêque de sa chambre à la salle d'apparat avant de le veiller nuit et jour en compagnie d'autres ecclésiastiques ; à la cathédrale, elle célèbre quotidiennement un office solennel ainsi qu'une messe de Requiem le 4 février. Le 7 février, à 9 heures, a lieu à l'évêché la levée du corps, puis son transfert à la cathédrale par les récollets, les prêtres du séminaire et le clergé - haut et bas chœur - de la cathédrale. Le cercueil de plomb est placé dans le chœur tendu pour l'occasion de velours noir. Pour garantir la solennité du moment, les portes de l'église sont fermées à clé à l'exception de « la grande porte qui est sous les orgues ", par laquelle est entrée la dépouille et devant laquelle veillent des hallebardiers chargés d' "empêcher le désordre ", tout comme devant l'évêché d'ailleurs. La cathédrale est en effet comble. La nef accueille « le peuple ", c'est-à-dire la bonne société : « les gentilshommes du côté de l'épître, les juges et les bourgeois du côté de l'évangile et les dames

31. Arch. dioc. de Saint-Brieuc, 1 CH 2, délibération capitulaire du 7 mai 1675.

32. Arch. dép. des Côtes-d'Armor, 2 G 3, mémoire du chapitre dressé à l'occasion du décès de Balthazar Grangier, 1679.

33. Arch. dioc. de Saint-Brieuc, 1 CH 2, délibération capitulaire du 24 mai 1675.

34. Arch. dép. des Côtes-d'Armor, 2 G 3, mémoire du chapitre dressé à l'occasion du décès de Balthazar Grangier, 1679. 
au milieu ". Les ecclésiastiques sont quant à eux assemblés dans le chœur. Tous s'apprêtent à participer à un long office de cinq heures : une messe au cours de laquelle " on n'a rien chanté en musique sinon la prose après l'épître et le De profundis pendant l'élévation ", précédée de l'Invitatoire et de trois Nocturnes. Si le chapitre est le véritable maître d'œuvre de la cérémonie, il reçoit l'appui de nombreux ecclésiastiques qui contribuent à lui donner toute la pompe nécessaire. Le chantre, premier dignitaire du chapitre, assiste l'abbé de Lusignan, neveu de Balthazar Grangier, qui officie, alors que le scolastique, Jean Cadier, chante la messe. Deux autres chanoines participent à l'office en tant que diacre et sous-diacre d'honneur pendant que l'ensemble du chapitre chante les leçons des Nocturnes. Par ailleurs, quatre vicaires sont désignés pour porter la chape et dix recteurs pour porter le cercueil. Pendant toute la cérémonie, six domestiques portent six flambeaux allumés.

Puis vient le moment de l'inhumation. À Saint-Brieuc, le très tridentin Le Porc de La Porte est inhumé aux ursulines en juin 1631, La Villazel est enterré en 1641 entre le chœur et le maître-autel " proche le trône où se mettaient les évêques pour officier dans l'ancien chœur ${ }^{35}$ ", alors qu'en 1675 le corps de Denis de La Barde "sera déposé dans la chapelle de la Trinité pour être au jour qu'il sera avisé par ci-après mis en terre ${ }^{36}$ " dans le chœur. À Tréguier, La Fruglaye est enterré le 24 décembre 1745 dans le chœur de la cathédrale "vers le trône épiscopal ${ }^{37}$ ", ce qui est la pratique courante ${ }^{38}$ mais n'exclut pas des entorses. Ainsi, en 1679, conformément au testament du prélat ${ }^{39}$, le cœur de Balthazar Grangier est transféré dans une logique toute tridentine, après l'enterrement de son corps à la cathédrale, au séminaire de Tréguier " où Monsieur le célébrant a porté ledit cœur couvert d'un drap et d'un crêpe noir ${ }^{40}$ ". L'évêque de SaintMalo Jean Du Bec est inhumé en 1610 selon la même pratique - assez classique au sein des élites - mais en délaissant la cathédrale : son corps est inhumé dans son abbaye de Mortemer en Normandie, province dont il est originaire ${ }^{41}$, alors que son cœur et ses entrailles sont déposés au pied du grand autel de l'église de Saint-Malo-de-Beignon ${ }^{42}$. C'est cepen-

35. Arch. dép. des Côtes-d'Armor, 1 G 218, délibération capitulaire du $1^{\mathrm{er}}$ juin 1641.

36. Arch. dioc. de Saint-Brieuc, 1 CH 2, délibération capitulaire du 24 mai 1675.

37. Arch. dép. des Côtes-d'Armor, 2 G 302, délibération capitulaire du 24 décembre 1745.

38. Un siècle plus tôt, c'est déjà le cas pour Noël des Landes (Arch. dép. des Côtesd'Armor, 2 G 287, délibération capitulaire du 20 août 1635).

39. Arch. dép. des Côtes-d'Armor, 2 G 3, testament de Balthazar Grangier, évêque de Tréguier, 15 février 1676.

40. Arch. dép. des Côtes-d'Armor, 2 G 3, mémoire du chapitre dressé à l'occasion du décès de Balthazar Grangier, 1679.

41. Guillotin de Corson, Amédée, Récits de Bretagne. Deuxième série, Rennes, Plihon et Hervé, 1892, p. 144.

42. Paroisse du centre du diocèse où les évêques de Saint-Malo possèdent une résidence. Deux autres évêques sont enterrés dans l'église paroissiale : François Thomé, mort en 1586, et Sébastien du Guémadeuc, décédé en 1702 (GuILLOTIN DE CoRSON, Amédée, Pouillé historique..., op. cit., p. 599 et 604. 
dant comme partout dans la cathédrale que les prélats sont le plus souvent inhumés. Si en règle générale leurs dépouilles sont placées dans un caveau dans le chœur, cette règle souffre quelques exceptions. Ainsi, en 1646, Achille de Harlay est mis en terre dans la nef " proche les fonts baptismaux sous une grande tombe de marbre bordée de tuffeau blanc ${ }^{43}$ ". Quant à Antoine-Joseph Des Laurents, constatant l'inconvenance qu'il y aurait à placer son corps sur celui de son prédécesseur encore bien conservé, le chapitre décide de le déposer dans une nouvelle fosse " en dehors mais joignant la grille du chœur du côté de l'épître sous une tombe de marbre blanc attenante au dit tombeau ${ }^{44}$ ".

La mort ou la translation d'un évêque marque également l'ouverture de la régale, cette période - qui se termine avec le serment de fidélité au roi du nouveau prélat - pendant laquelle, dans le domaine spirituel, le souverain nomme aux bénéfices sans charge d'âmes du diocèse vacant et, en matière temporelle, perçoit les revenus de la manse ${ }^{45}$. Débutent aussi les procédures qui conduisent au règlement de la succession de l'évêque ${ }^{46}$ : on procède ainsi rapidement à l'inventaire de ses biens en cas de décès et, dans tous les cas, à l'estimation des travaux à accomplir à l'évêché ${ }^{47}$. Dans le même temps, il convient de veiller à l'application des dispositions testamentaires du défunt ${ }^{48}$.

Toutes ces opérations sont les indices patents d'une logique sousjacente. Si les évêques s'affirment progressivement au cours de la période comme les hommes forts des diocèses, le chapitre assure quant à lui symboliquement la continuité de l'autorité et leur direction spirituelle. Aux yeux des chanoines, les évêques se succèdent pendant que le chapitre incarne la permanence, les accompagnant les uns après les autres vers leur dernière demeure. L'image est forte et symbolique dans les cités épis-

43. Ibidem, p. 603.

44. Arch. dép. d'Ille-et-Vilaine, 1 G 268, délibération capitulaire du 24 octobre 1785.

45. En réalité, à partir de 1641, le roi fait don du revenu de l'évêché vacant au nouvel évêque (BLET, Pierre, "Régale ", dans BÉLY, Lucien (dir.), Dictionnaire de l'Ancien Régime, Paris, Presses universitaires de France, 1996, p. 1064).

46. Qui ne relève pas de la responsabilité du chapitre (DuRAND DE MaIllane, Pierre Toussaint, Dictionnaire de droit canonique et de pratique bénéficiale, Paris, Bauche, 1761, t. 2, p. 743).

47. Pour Tréguier, par exemple, Arch. dép. des Côtes-d'Armor, 2 G 4, succession épiscopale : inventaires du manoir épiscopal après décès ou mutation de l'évêque (1694, 1762, $1767,1768,1773,1775)$.

48. Précisons qu'en dépit de l'étroitesse du corpus, les testaments d'évêques de nos trois diocèses devront faire l'objet d'une étude. On dispose comme cadre général de l'article de référence de BERGiN, Joseph, "Les évêques du Grand Siècle devant la mort d'après leurs testaments ", Revue d'histoire de l'Eglise de France, t. 94, 2008, p. 263-281. Pour Saint-Brieuc, sont conservés ceux de Denis de La Barde (Arch. dép. des Côtesd'Armor, 1 G 5, testament, 1675) et de Hervé-Nicolas Thépault du Breignou (Arch. dép. des Côtes-d'Armor, $40 \mathrm{~J}$ 8, testament, 1766) ; pour Tréguier, ceux d'Adrien d'Amboise et de Balthazar Grangier (Arch. dép. des Côtes-d'Armor, 2 G 3, testaments, 1616 et 1679) ; pour Saint-Malo, celui de Jean du Bec (1610) est donné dans JouON DES LONGRAIS, Frédéric, Jacques Doremet, sa vie, ses ouvrages, Rennes, Plihon et Hervé, 1894, p. 27-33. 
copales les jours d'obsèques. Elle l'est d'autant que dès la disparition du prélat le chapitre s'est vu confier l'administration du diocèse.

\section{Le chapitre au pouvoir}

Entre la fin du XVI ${ }^{\mathrm{e}}$ et la fin du XVIII ${ }^{\mathrm{e}}$ siècle, les diocèses de Tréguier, SaintBrieuc et Saint-Malo connaissent respectivement vingt vacances pour le premier et treize pour les deux autres ${ }^{49}$. Leurs durées, sans atteindre celle qui, à la suite du décès de Nicolas Langelier à Saint-Brieuc, s'étend de manière exceptionnelle de 1595 à $1602^{50}$, sont variables. Officiellement, la vacance s'ouvre au décès de l'évêque et se termine lors de la prise de possession de son successeur. Ainsi, à l'annonce du décès subit d'Antoine Joseph des Laurents ${ }^{51}$, les chanoines de Saint-Malo s'empressent de déclarer " le siège épiscopal vacant et toute la juridiction spirituelle leur appartenir dans tout le diocèse ${ }^{52}$ ". Leurs confrères de Saint-Brieuc mentionnent quant à eux lors de l'arrivée de François Bareau de Girac que « les vicaires généraux (sic) ont déclaré que par la prise de possession de Monsieur notre évêque de cet évêché, la juridiction que le chapitre leur avait donnée d'exercer le vicariat pendant la vacance du siège a cessé53 ". En cas de démission ou de résignation, c'est la date de la préconisation à Rome qui marque le début de la vacance ${ }^{54}$. Si entre le milieu du $\mathrm{XVI}^{\mathrm{e}}$ et la fin du $\mathrm{XVIII}^{\mathrm{e}}$ siècle les durées moyennes des vacances sont de l'ordre de 14 mois à Tréguier, 15 à Saint-Brieuc et 16 à Saint-Malo ${ }^{55}$, l'essentiel réside dans la tendance au raccourcissement des périodes de transition. Sans surprise,

49. Sont exclues de l'étude les fins d'épiscopat liées au début de la Révolution de Le Mintier à Tréguier, Régnault de Bellescize à Saint-Brieuc, Cortois de Pressigny à SaintMalo.

50. Langelier décède le 24 septembre 1595. Le chapitre élit les officiers pour la vacance le 2 octobre, un nouvel official étant nommé le 9 juin 1597 (Arch. dép. des Côtes-d'Armor, 1 G 218, registre des délibérations capitulaires, 1587-1733). L'évêché n'est de nouveau pourvu qu'une fois la paix revenue et la région acquise à Henri IV en 1601, mais ce n'est que le 18 mars 1602 que le nouveau prélat, Pierre de Marconnay, prend possession par procuration (Id.). Au titre des longues vacances, on observe aussi celle qui débute à Tréguier à la mort de François de La Tour en 1587 pour se terminer après 1593, ou à Saint-Malo celle qui s'étend du décès de François Thomé en 1586 à l'arrivée de Charles de Bourgneuf en 1590. Notons par ailleurs qu'à Saint-Malo le successeur de Guillaume Le Gouverneur, décédé le 25 juin 1630, ne sera nommé que le 16 août 1631 à cause du refus persistant d'un premier successeur, le capucin Octavien de Marillac dit le père Michel de Paris (JouOn DEs LongraIs, Frédéric, Jacques Doremet..., op. cit., p. 47).

51. Voir supra note 27.

52. Arch. dép. d'Ille-et-Vilaine, 1 G 268, délibération capitulaire du 16 octobre 1785.

53. Il s'agit de sa prise de possession par procuration : Arch. dép. des Côtes-d'Armor, 1 G 50, insinuations ecclésiastiques, 2 octobre 1766. Notons que les mentions claires de début et de fin de vacance sont rares et concernent le XVIII ${ }^{\mathrm{e}}$ siècle. La plupart du temps, il faut donc procéder à une lecture attentive des registres d'insinuations afin de repérer les changements de formule initiale des actes (" le chapitre le siège vacant ").

54. Durand de Malllane, Pierre-Toussaint, Dictionnaire de droit canonique..., op. cit., p. 744 .

55. Données fondées sur respectivement onze, treize et neuf vacances exploitables. 
les vacances de la période des guerres de religion sont les plus longues ${ }^{56}$; la stabilisation politique, l'application des décrets tridentins, la volonté des nouveaux évêques d'exercer la plénitude de leurs pouvoirs et de leurs droits après une phase d'affaiblissement de leur autorité au profit des chapitres ${ }^{57}$ produisent ensuite leurs effets et la durée des interépiscopats a tendance à diminuer, surtout dans la seconde moitié du XVIII ${ }^{\mathrm{e}}$ siècle ${ }^{58}$, d'autant qu'un seul des trois diocèses est concerné par les conséquences de l'affrontement entre Louis XIV et les papes Innocent XI et Innocent XII autour de la régale entre 1682 et $1693^{59}$.

\section{Tableau 1 - La durée des interépiscopats (données arrondies au mois inférieur)}

\begin{tabular}{|l|c|c|c|}
\hline & Saint-Brieuc & Saint-Malo & Tréguier \\
\hline $\begin{array}{l}2^{\text {de }} \text { moitié du } \\
\text { XVII } \text { siècle }\end{array}$ & 78 mois $(1$ cas $)$ & 25 mois $(2$ cas $)$ & 12 mois $(1$ cas $)$ \\
\hline XVIII $^{\mathrm{e}}$ siècle & 14 mois $(5$ cas $)$ & 22 mois $(3$ cas $)$ & 34 mois $(3$ cas $)$ \\
\hline $\mathrm{XVIIII}^{\mathrm{e}}$ siècle & 7 mois $(7$ cas $)$ & 9 mois $(4$ cas $)$ & 7 mois $(7$ cas $)$ \\
\hline
\end{tabular}

Dès l'annonce de la vacance du siège, le chapitre fait procéder à un inventaire des biens et archives de l'évêché et organise la perception de ses revenus dans une double optique : veiller à la fois sur les intérêts de la compagnie et de l'ordinaire. En réalité, souvent, la procédure est lancée par le nouvel évêque ou les héritiers de l'ancien... sous le regard vigilant des compagnies. Ainsi, après la mort d'Adrien d'Amboise, alors que l'inventaire a commencé "se sont présentés vénérables messires Mathurin Lostis, Guillaume André chanoines en l'église cathédrale de Tréguier, lesquels nous ont dit avoir ce jour été députés par le vénérable chapitre dudit Tréguier pour assister au présent inventaire en conservation des droits

56. À la charnière des XVI ${ }^{\mathrm{e}}$ et XVII ${ }^{\mathrm{e}}$ siècles, Dol, Nantes, Vannes et Rennes sont aussi plus ou moins longtemps privés d'évêque (PocQueT DU HAUT-Jussé, Barthélemy Amédée, " Les évêques de Bretagne... ", art. cit., p. 36-37).

57. RESTIF, Bruno, "Synodes diocésains, concile provincial et législation dans la province ecclésiastique de Tours du concile de Trente au milieu du XVII ${ }^{\mathrm{e}}$ siècle ", dans Aoun, Marc, TUFFERY-ANDRIEU, Jeanne-Marie (dir.), Conciles provinciaux et synodes diocésains du concile de Trente à la Révolution française. Défis ecclésiaux et enjeux politiques?, Strasbourg, Presses universitaires de Strasbourg, 2010, p. 209.

58. Dans la seconde moitié du XVIII ${ }^{\mathrm{e}}$ siècle, les données sont les suivantes : 6 mois $1 / 2$ à Saint-Brieuc (3 cas), 6 à Saint-Malo (2 cas) et à Tréguier (5 cas).

59. En effet, seule la confirmation pontificale du Trégorrois Eustache Le Sénéchal de Carcado est retardée (Minols, Georges, La Bretagne des prêtres..., op. cit., p. 142). Dans les diocèses concernés, le candidat de la monarchie participe souvent au gouvernement de son diocèse en tant que vicaire capitulaire jusqu'à réception de ses bulles romaines (BERgin, Joseph, Crown, Church and Episcopate under Louis XIV, New Haven, Yale University Press, 2004, p. 140). 
qu'ils peuvent prétendre dans la succession dudit feu seigneur évêque ${ }^{60}$ "; à Saint-Malo, lors du décès d'Antoine-Joseph des Laurents, les chanoines Mathurin Frostin et Guillaume Potier du Parc ${ }^{61}$ " sont priés d'assister à l'apposition et à la levée du scellé, ainsi qu'à l'inventaire des titres et papiers de Monseigneur, à l'effet de revendiquer ceux qui intéressent l'évêché et le chapitre ${ }^{62}$ ". Le chapitre dispose de huit jours pour, conformément au concile de Trente, établir un official ou grand vicaire " gradué ou autrement capable " sachant que "s'il y a des chanoines capables dans le chapitre, ils doivent être préférés " à tout autre. En effet, le chapitre ne gouverne pas le diocèse en corps mais par l'intermédiaire de vicaires dont le nombre " dépend de l'état et de la grandeur du diocèse, et même de l'usage ${ }^{63}$ ". Dans la pratique, les chapitres nomment sans tarder une nouvelle administration à la tête du diocèse. Ainsi, à Saint-Brieuc ( 7 cas sur 10 exploitables) et à Saint-Malo (dans les 4 cas connus) l'opération a lieu en général dans les deux jours ${ }^{64}$; à Tréguier, le délai est souvent un peu plus long (3 cas sur 8 à 4 jours ou plus). Il s'agit en règle générale de nommer des vicaires capitulaires - dans les trois diocèses les vicaires sont choisis au sein des chapitres $^{65}$ - et un official, parfois un secrétaire et un vice-gérant de l'officialité. Malheureusement, la documentation mise en œuvre ne permet pas toujours d'identifier tous les vicaires capitulaires ${ }^{66}$. Sources idéales, les registres d'insinuations ecclésiastiques et les registres de délibérations capitulaires sont inégalement conservés ou accessibles ${ }^{67}$ et ne recèlent pas toujours toutes les informations souhaitées ${ }^{68}$. En définitive, il est possible de s'appuyer sur 17 cas bien documentés ${ }^{69}-$ sept à Saint-Brieuc, trois à Tréguier, sept à Saint-Malo - complétés par quelques dossiers d'appoint ${ }^{70}$.

60. Arch. dép. des Côtes-d'Armor, 2 G 5, inventaire des titres de l'évêché de Tréguier fait après la mort de Mgr d'Amboise, 13 novembre 1616. Sur les chanoines cités, se reporter à MinoIs, Georges, "Liste alphabétique et biographique des chanoines de Tréguier aux XVII ${ }^{\mathrm{e}}$ et XVIII ${ }^{\mathrm{e}}$ siècles ", Mémoires de la Société d'émulation des Côtes-du-Nord, t. CXI, 1982, p. 133 et 145 .

61. Charles, Olivier, Chanoines de Bretagne..., op. cit., notices 240 p. 383 et 623 p. 433.

62. Arch. dép. d'Ille-et-Vilaine, 1 G 268, délibération capitulaire du 16 octobre 1785.

63. Durand de Maillane, Pierre Toussaint, Dictionnaire de droit canonique..., op. cit., p. 488.

64. Les conditions particulières de la mort de Frétat de Boissieux, déjà évoquées, allongent exceptionnellement le délai à sept jours.

65. Nous n'avons repéré que quatre vicaires capitulaires non chanoines sur un échantillon de 57 individus (annexe 2) : Antoine Joseph des Laurents à Saint-Malo et Louis Emmanuel de Bizien du Lézart à Tréguier en 1767, René Louis Le Mintier à Saint-Brieuc en 1770 et Yves-Marie de Bizien du Lézart à Tréguier en 1773.

66. Que les sources appellent aussi vicaires généraux ou grands vicaires.

67. Ainsi, à Tréguier, du fait de l'incommunicabilité de plusieurs registres d'insinuations ecclésiastiques, quatre des huit transitions potentiellement relatées échappent au chercheur. À Saint-Brieuc, les actes capitulaires sont quasi inexistants alors qu'à Saint-Malo ce sont ceux des périodes interépiscopales qui font défaut.

68. C'est notamment le cas des actes les plus anciens.

69. Avec identification des vicaires généraux en place à la fin de l'épiscopat, des vicaires capitulaires de la vacance, des vicaires généraux nommés par le nouvel évêque.

70. Au total, l'échantillon contient 24 vacances : huit pour chaque diocèse. 
Ce sont moins les usages de chacun des chapitres que les évolutions de longue durée qui semblent intéressantes ici. En effet, plus que le nombre de vicaires capitulaires, variable selon les compagnies, leur inflation avec un décalage chronologique certain selon les diocèses frappe l'observateur. En effet, dès 1720 ils passent à 5 ou 6 à Saint-Brieuc, alors qu'il faut attendre 1767 pour les voir passer de 2 ou 3 à 5 ou 6 à Tréguier et de 1 ou 2 à plus de 4 à Saint-Malo ${ }^{71}$. À quoi attribuer une telle tendance? À défaut de certitudes, quelques pistes peuvent être suggérées : les leçons tirées des répercussions des absences de l'évêque sur l'efficacité de l'administration diocésaine? l'augmentation des tâches liées à une bureaucratisation accrue de l'appareil épiscopal? le partage mieux assuré des travaux en découlant? une approche plus collégiale des responsabilités? À défaut d'analyses diocésaines fines, il faut se contenter des stipulations intemporelles des lettres de mission remises par le chapitre. Elles rendent compte des droits et responsabilités étendus des chapitres pendant les vacances ${ }^{72}$ : accorder les dispenses, absoudre de l'excommunication, corriger et punir les ecclésiastiques délinquants, instituer les candidats aux bénéfices à charge d'âmes présentés par les patrons, administrer et enregistrer les résignations et les permutations. En revanche, en matière d'ordre, le chapitre ne peut qu'accorder des dimissoires. Avant toute chose, les vicaires capitulaires s'inscrivent dans la continuité de l'action de l'évêque précédent. Ceux de Tréguier indiquent en 1731 qu'ils entendent continuer à faire observer les statuts du diocèse et rappellent le rôle important du séminaire et des conférences ecclésiastiques dans le bon encadrement des fidèles ${ }^{73}$. Plus spécifiquement, à Saint-Brieuc, le chapitre doit de surcroît défendre son droit à lever les dîmes de l'évêché pendant la régale. C'est un privilège dont il jouit au moins depuis le $\mathrm{XV}^{\mathrm{e}}$ siècle, mais qui est régulièrement contesté par les nouveaux évêques et lui a été confirmé par le roi en 1525, 1596, 1618, 1653, 1705, 1727 ${ }^{74}$. Il lui faut parfois rappeler son bon droit très longtemps : par exemple, en 1767, il réclame à François Bareau de Girac le montant des dîmes que Hervé Nicolas Thépault du Breignou, son prédécesseur, ne lui a pas versées ${ }^{75}$.

L'administration du diocèse est confiée à un personnel bien typé. Les vicaires capitulaires sont en effet des chanoines expérimentés : leur âge et leur ancienneté dans les compagnies en témoignent. Par ailleurs, ils sont plus gradués que la moyenne de leurs confrères. Un nombre non négli-

71. Voir annexe 2. Le caractère dualiste de l'administration malouine doit-il être invoqué? L'existence de deux officialités (Dinan et Porhoët), donc de deux officiaux, deux promoteurs, un vice-official et un vice-promoteur justifierait-elle la nomination d'un seul vicaire capitulaire jusqu'à la transition entre Desmaretz et La Bastie en 1739 ?

72. DuRand de Maillane, Pierre-Toussaint, Dictionnaire de droit canonique..., op. cit., p. $742-743$.

73. Arch. dép. des Côtes-d'Armor, 2 G 278, mandement pour la conduite du diocèse de Tréguier pendant la vacance du siège, 9 août 1731 .

74. Arch. dép. des Côtes-d'Armor, 1 G 201, confirmation des privilèges du chapitre de Saint-Brieuc par lettre patente, 13 novembre 1727.

75. Arch. dép. des Côtes-d'Armor, $40 \mathrm{~J}$ 8, réclamation du chapitre cathédral de SaintBrieuc à la mort de Thépault du Breignou, 4 octobre 1767. 
geable a de plus une expérience préalable de vicaire général, voire, en fonction des aléas, de vicaire capitulaire. Enfin, plusieurs peuvent se prévaloir d'autres fonctions importantes à la tête des diocèses. Jacques Doremet est ainsi l'inamovible secrétaire de l'évêque de Saint-Malo Jean Du Bec, Guillaume Allain de Beaulieu celui de l'évêque de Saint-Brieuc Louis Marcel de Coëtlogon, Pierre Nicolas Rousselin du Rocher celui de La Bastie à SaintMalo. Six ont rempli la fonction d'official diocésain, trois ont représenté le clergé diocésain lors d'un concile provincial à Tours, trois Briochins ont occupé l'important poste d'examinateur du concours pour les cures. Certains présentent ainsi un profil particulièrement adapté à la mission. Par exemple, lorsque le Briochin Mathias-Claude Soubens est désigné en 1775, il a été chanoine de la cathédrale de Quimper, recteur de Plusquellec dans le diocèse de Quimper, vicaire capitulaire en 1766 et 1770; il est chanoine de la cathédrale de Saint-Brieuc depuis 1753, scolastique du chapitre et official du diocèse de Saint-Brieuc depuis 1760, théologal du chapitre cathédral depuis 1763 , vicaire général depuis $1770^{76}$. En définitive, les chanoines en apparence ordinaires qui accèdent à cette fonction sont largement minoritaires ${ }^{77}$. C'est donc l'impression d'une savante combinaison entre les hommes forts des chapitres - au titre desquels les dignitaires - et ceux qui ont une expérience à la tête du diocèse qui semble se dégager, le tout au service de la meilleure transition possible.

Ces périodes de vacance sont tout sauf anecdotiques pour les chapitres. En effet, elles s'inscrivent dans une temporalité de long terme qui leur est défavorable. Certes, au spirituel, ces corps intermédiaires de la société d'Ancien Régime conservent leurs attributions tout au long de la période. Ils assurent bien la permanence du culte divin dans l'église-mère du diocèse et demeurent des acteurs majeurs de la vie sociale et économique des villes et des campagnes proches. Mais, tout en restant localement des institutions de premier plan, ils perdent en plusieurs étapes une partie de leur influence sur les affaires diocésaines. D'abord, le concordat de Bologne leur retire au début du $\mathrm{XvI}^{\mathrm{e}}$ siècle l'élection des évêques dont le choix devient une prérogative du souverain. Quelques décennies plus tard, le concile de Trente les soumet étroitement à la juridiction épiscopale, notamment au droit de visite des prélats à des fins disciplinaires et spirituelles. Dans le contexte de la mise en œuvre de la Réforme catholique, ils ne sont donc plus le sénat de l'évêque mais un corps qui lui est étroitement subordonné. Cette nouvelle réalité est cause de crispation dans de nombreuses cités épiscopales au cours du XVII ${ }^{\mathrm{e}}$ siècle surtout, en Guyenne ${ }^{78}$ comme dans le Trégor $^{79}$ ou ailleurs en Bretagne ${ }^{80}$, mais parfois jusqu'au début du siècle

76. Données provenant d'une enquête collective en cours sur les chanoines de la cathédrale de Saint-Brieuc entre le XIII ${ }^{\mathrm{e}}$ et le XXI ${ }^{\mathrm{e}}$ siècle.

77. 14 sur 57.

78. LouPĖs, Philippe, Chapitres et chanoines de Guyenne..., op. cit., p. 343-366.

79. MinoIs, Georges, La Bretagne des prêtres..., op. cit., p. 99-109.

80. Pocquet du Haut-Jussé, Barthélemy Amédée, « Les évêques de Bretagne... ", art. cit., p. $37-39$. 
Tableau 2 - Le profil des vicaires capitulaires

\begin{tabular}{|c|c|c|c|}
\hline & Saint-Brieuc & Saint-Malo & Tréguier \\
\hline Corpus & 20 & 14 & 23 \\
\hline $\begin{array}{l}\text { - Ancienneté dans le chapitre } \\
\text { - Durée moyenne d'un canonicat } \\
\text { au xVIII }^{\mathrm{e}} \text { siècle }^{\mathrm{a}}\end{array}$ & $\begin{array}{l}22 \text { ans } \\
19 \text { ans }\end{array}$ & $\begin{array}{l}19 \text { ans } \\
21 \text { ans }\end{array}$ & $\begin{array}{l}21 \text { ans } \\
17 \text { ans }\end{array}$ \\
\hline - Dignités & 10 & 4 & 10 \\
\hline $\begin{array}{l}\text { - Gradués } \\
\text { - Proportion dans le chapitre au } \\
\text { XVIII }^{\mathrm{e}} \text { siècle }^{\mathrm{b}}\end{array}$ & $\begin{array}{l}12 \text { soit } 60 \% \\
44 \%\end{array}$ & $\begin{array}{l}8 \text { soit } 57 \% \\
47 \%\end{array}$ & $\begin{array}{l}15 \text { soit } 65 \% \\
50 \%\end{array}$ \\
\hline - Expérience de vicaire capitulaire & 10 & 2 & 4 \\
\hline - Expérience de vicaire général & 10 & 10 & 13 \\
\hline - Âge moyen & 56 ans & 62 ans & 47 ans \\
\hline
\end{tabular}

a. Charles, Olivier, “ Les nobles dignités, chanoines et chapitres » de Bretagne. Chanoines et chapitres cathédraux de Bretagne au siècle des Lumières, thèse de doctorat (Jean Quéniart, dir.), université Rennes 2, 2002, volume III, annexe 7, p. 493.

b. Ibidem, annexe 23, p. 571.

suivant comme à Saint-Malo ${ }^{81}$. Par la suite, la résistance de ces corps, dont les racines s'ancrent dans la période médiévale, à l'esprit réformateur postconciliaire cède le pas à une cohabitation apaisée. Cependant, la tendance au raccourcissement des transitions traduit certainement autant un souhait réel de mettre rapidement fin à la régale qu'une volonté stratégique des évêques de prendre en main au plus tôt leur territoire afin d'affirmer très vite la plénitude de leur autorité. L'intermède prend ainsi fin avec la prise de possession du nouvel évêque qui reçoit en général auparavant des lettres de vicaire général du diocèse ${ }^{82}$. Cela dit, l'on comprend bien l'importance que revêt la direction du diocèse sede vacante pour un chapitre dans un tel contexte. C'est bien ce que rappelle très clairement à tous le chapitre cathédral de Quimper au travers de l'un des huit panneaux de la chaire qu'il commande en 1679. Face au prélat agonisant (sous les traits de saint Corentin), on y voit en effet, debout, un chanoine qui, après lui avoir administré les derniers sacrements, lui adresse « une ultime exhortation en une spectaculaire inversion des rôles ${ }^{83}$ ".

81. ChARLEs, Olivier, "Quand un évêque visite son chapitre... ", art. cit.

82. On en trouve rarement trace dans les registres d'insinuations ecclésiastiques. La mention de celles qui sont envoyées par le chapitre de Saint-Brieuc à Jules-Basile Ferron de La Ferronnays en 1770 constitue en cela une exception (Arch. dép. des Côtes-d'Armor,

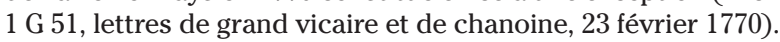

83. Provost, Georges, "Quand saint Corentin monte en chaire. Hagiographie et jeux d'influence à la cathédrale de Quimper vers 1680 ", dans CASSARD, Jean-Christophe, LAMBERT, Pierre Yves, PICARD, Jean-Michel, YEURC'H, Bertrand, (dir.), Mélanges offerts au professeur Bernard Merdrignac, Britannia Monastica $n^{\circ}$ 17, Landévennec, 2013, p. 386. 


\section{La prise en main du diocèse par le nouvel évêque}

Depuis le concordat de 1516 conclu entre François ${ }^{\text {er }}$ et Léon X les évêques sont désignés par le souverain qui leur adresse un brevet de nomination et auquel ils prêtent serment ${ }^{84}$. Entre ces deux formalités, le souverain pontife leur donne l'investiture canonique par bulle après une enquête - l'information romaine - qui aura conduit les futurs prélats à répondre de leur état civil, à présenter leur carrière et à envoyer à Rome, avant que la logique gallicane ne s'oppose à cette pratique au cours du XVII siècle $^{85}$, un rapport ad limina ${ }^{86}$. La cérémonie du sacre peut alors avoir lieu. Il ne restera plus aux nouveaux prélats qu'à prendre possession de leurs bénéfices, souvent en deux temps. En effet, seulement 11 des 36 évêques pour lesquels nous sommes renseignés prennent directement possession. Les autres confient d'abord cette procédure à un procureur qui, accompagné d'un ou plusieurs notaires apostoliques, présente leurs bulles de nomination au président du chapitre ${ }^{87}$. Puis, sous la conduite de deux ou trois

84. Sur la procédure de nomination des évêques sous l'Ancien Régime, se reporter à Plongeron, Bernard, La vie quotidienne du clergé français au XVII' siècle, Paris, Hachette, 1974, p. 94-101 et Peronnet, Michel, " Évêques ", dans BéLY, Lucien (dir.), Dictionnaire de l'Ancien Régime..., op. cit., p. 524. Précisons que, du fait de son rattachement postérieur au royaume, le concordat de Bologne ne s'applique pas à la Bretagne qui demeure pays d'obédience pontificale. Ce sont donc des indults pontificaux qui donnent au roi ses droits de nomination aux évêchés de la province (BERTHELOT DU CHESNAY, Charles, Les prêtres séculiers..., op. cit., p. 219).

85. VENARD, Marc (dir.), Histoire du christianisme. T. 8. Le temps des confessions (15301620), Paris, Desclée, 1992, p. 253.

86. Depuis 1585 , les évêques français sont théoriquement obligés de se rendre tous les quatre ans à Rome pour y faire un rapport sur l'état de leur diocèse. Cette visite ad limina Apostolorum (" sur le seuil des apôtres ") se résume aux xvII ${ }^{\mathrm{e}}$ et $\mathrm{xvIII}^{\mathrm{e}}$ siècles au simple envoi d'un rapport établi devant un notaire parisien en présence du nonce par le futur évêque. Il se décompose théoriquement en plusieurs chapitres : situation, limites et état matériel du diocèse, notices sur l'évêque, le chapitre, le clergé séculier, le clergé régulier masculin et féminin -, le séminaire, les confréries, les fidèles. En conclusion, l'évêque peut formuler des questions ou des requêtes. Celui du dernier évêque de Saint-Brieuc (Arch. nat., minutier central des notaires parisiens, étude LXXXII, 532, information pour l'évêché de Saint-Brieuc pour M. Regnault de Bellescize, 19 décembre 1774) offre ainsi une description succincte du diocèse à la fin de l'Ancien Régime. Dans la mesure où aucun rapport $a d$ limina n'est conservé dans les archives romaines pour la France du nord-ouest (VENARD, Marc, "Les rapports de visites ad limina des évêques de France sous l'Ancien Régime ", dans VinCENT, Bernard, BoutRY, Philippe (dir.), Les chemins de Rome. Les visites ad limina à l'époque moderne dans l'Europe méridionale et le monde hispano-américain ( $16^{e}-19^{e} \mathrm{~s}$.), Rome, Ecole française de Rome, 2002, p. 101-121), celui d'un évêque rennais de la fin du $\mathrm{XVI}^{\mathrm{e}}$ siècle étudié par Bruno Restif n'en est que plus précieux (RESTIF, Bruno, « Le rapport ad limina d'Arnaud d'Ossat, évêque de Rennes, en 1598 ", dans CALVEz, Ronan, GullLou, Chantal, Jarnoux, Philippe, Tranvouez, Yvon (dir.), Langues de l'histoire, langues de la vie. Mélanges offerts à Fañch Roudaut, Brest, Association Les amis de Fañch Roudaut, 2005, p. 107-118). Cela dit, la promesse de se rendre régulièrement à Rome figure jusqu'à la fin de l'Ancien Régime dans le serment de fidélité au Siège romain (Plongeron, Bernard, $L a$ vie quotidienne du clergé français..., op. cit., p. 98).

87. Cette proportion est certainement sous-estimée si l'on en croit Anne-Nicolas Borie, vicaire capitulaire puis vicaire général de Le Mintier à Tréguier, qui confie à son évêque : " tous vos prédécesseurs ont pris comme vous possession par procureur et ensuite en 
chanoines, il accomplit les gestes symboliques de la prise de possession ${ }^{88}$ et prête serment au nom de son évêque ${ }^{89}$, mettant ainsi fin à la vacance du siège. Qui sont ces procureurs? À de rares exceptions près, on a affaire à des chanoines ou à des dignitaires de la cathédrale, conformément à la pratique en vigueur dans les cathédrales du royaume ${ }^{90}$. Ceci apparaît clairement lorsque l'on examine les profils de onze procureurs briochins bien documentés ${ }^{91}$ : la mission revient quatre fois au doyen, premier dignitaire, une fois au trésorier, second dignitaire, deux fois à l'archidiacre de Penthièvre, troisième dignitaire, une fois au scolastique, cinquième dignitaire. Il semble bien que la clé soit ici : le chapitre, titulaire de l'évêché en l'absence de l'évêque, reçoit, au travers notamment de ses dignitaires, la mission d'en confier la destinée à l'impétrant. Seul Pierre Demay, choisi par Melchior de Marconnay ${ }^{92}$, et François Lestic de Vaudurand, chanoine de la collégiale Saint-Guillaume de Saint-Brieuc choisi par Hardouin Fortin de La Hoquette ${ }^{93}$, dérogent. L'existence de relations antérieures peut certainement être invoquée si l'on se fie à la désignation de René Porée du Parc par Vincent-François Desmaretz en 1702 à Saint-Malo ${ }^{94}$. Mais il est vrai que ce dernier est également chantre et premier dignitaire du chapitre. Peutêtre un tel lien est-il également opérant dans le cas du briochin Charles Jacques Denis de Becdelièvre, chanoine non-dignitaire, procureur de Jules Ferron de La Ferronnays en avril $1770^{95}$, d'autant que l'évêque l'a nommé vicaire général dès qu'il en a fait son procureur le jour de son sacre et

personne à leur entrée solennelle " (Arch. dép. des Côtes-d'Armor, 1 G 2, lettre de Borie à Le Mintier, 11 décembre 1780).

88. Ainsi, à Saint-Brieuc, Louis de Labat, agissant pour Louis Frétat de Boissieu en 1705, après être sorti de la cathédrale, va " y rentrer, ouvrir et fermer la porte, prendre et donner de l'eau bénite, toucher la chaire destinée aux prédicateurs, monter en icelle et descendre, faire à genoux dévotes prières dans la nef devant l'image du crucifix et au chœur devant le grand autel qu'il a baisé au milieu et touché le tabernacle du SaintSacrement et icelui ouvert et refermé, et descendu au chœur a touché et tourné l'aigle du pupitre, s'est assis dans l'une et l'autre chaire destinée aux stalles et séances des seigneurs évêques dudit Saint-Brieuc, s'y est tenu debout et prosterné à genoux pendant lesquelles séances dudit sieur de Labat lesd. sieurs chanoines députés ont exposé, et l'un d'eux a publié à l'aigle du pupitre, la teneur desd. bulles " (Arch. dép. des Côtes-d'Armor, 1 G 38, délibération capitulaire du 21 octobre 1705).

89. Il s'agit de respecter les droits du chapitre (voir, par exemple Arch. dép. des Côtesd'Armor, 1 G 4, touchant les prises de possession par les évêques mes prédécesseurs de l'évêché de Saint-Brieuc, 9 mars 1632) ; de payer les droits coutumiers du chapitre : sommes en argent pour le pain du chapitre, vin d'Espagne pour les dignitaires et les simples chanoines, les officiers du chapitre, les choristes, une chapelle garnie, des chasubles, des chappes à Saint-Malo par exemple (Arch. dép. d'Ille-et-Vilaine, 1 G 54/1, délibération capitulaire du 23 octobre 1702).

90. Voir sur ce point BRUNET, Jean-Louis, Le parfait notaire apostolique et procureur des officialités (seconde édition complétée par P.-T. Durand de Maillane), Lyon, Duplain, 1775, p. 527.

91. Voir annexe 3 .

92. Arch. dép. des Côtes-d'Armor, 1 G 218, délibération capitulaire du 18 mars 1602.

93. Arch. dioc. de Saint-Brieuc, $1 \mathrm{CH}$ 2, délibération capitulaire du 10 mai 1676.

94. CHARLES, Olivier, "Quand un évêque visite son chapitre... ", art. cit., p. 72.

95. Arch. dép. des Côtes-d'Armor, 1 G 51, délibération capitulaire du 8 avril 1770. 
reconduit un mois après ${ }^{96}$; de Pierre Demay, prêtre du diocèse d'Amiens dont Marconnay fera un chanoine, un archidiacre et un vicaire général ${ }^{97}$; ou encore du chanoine trégorrois Jean Le Soulfour, " particulier ami ${ }^{98}$ " et vicaire général de Balthazar Grangier. Des liens familiaux peuvent vraisemblablement aussi expliquer certains choix : à Saint-Malo, Guillaume Le Gouverneur a ainsi fait de son neveu son procureur... avant de le pourvoir du doyenné du chapitre et d'un mandat de vicaire général ${ }^{99}$. Cela étant, constat qu'il conviendrait de réinterroger, les sept procureurs du corpus briochin du siècle des Lumières sont vicaires généraux de l'ancien évêque et cinq sont vicaires capitulaires ${ }^{100}$. C'est donc le visage d'un administrateur chevronné - dignitaire, ancien vicaire général, vicaire capitulaire - que semble présenter le procureur de l'évêque.

L'entrée solennelle des évêques dans les cités épiscopales, dont la prise de possession personnelle est le point d'orgue ${ }^{101}$, n'est malheureusement pas systématiquement mentionnée dans les registres d'insinuations ecclésiastiques ni d'ailleurs obligatoirement décrite dans les registres de délibérations des chapitres, pas plus que dans les registres des communautés de ville. Par exemple, lorsque Hardouin Fortin de La Hoguette arrive à Saint-Brieuc en 1676 , le secrétaire du chapitre se contente de noter que "Monsieur notre évêque fit hier son entrée et prit possession en personne avec les cérémonies ordinaires et prêta le serment aussi ordinaire ${ }^{102}$ ". Le cérémonial est en effet fixé depuis longtemps et connu de tous ${ }^{103}$ et il faut se contenter d'informations éparses ${ }^{104}$. Cela n'exclut cependant pas des

96. Arch. dép. des Côtes-d'Armor, 1 G 51, lettres de vicaire général pour Charles-JacquesDenis de Becdelièvre, 8 avril et 10 mai 1770 .

97. Informations provenant d'une enquête collective en cours sur les chanoines de la cathédrale de Saint-Brieuc du XIII ${ }^{\mathrm{e}}$ au XXI ${ }^{\mathrm{e}}$ siècle.

98. Arch. dép. des Côtes-d'Armor, 2 G 3, testament de Balthazar Grangier, évêque de Tréguier, 15 février 1676.

99. JouOn DES LONGRAIS, Frédéric, Jacques Doremet..., op. cit., p. 39.

100. Voir annexe 3.

101. Elle intervient en général cinq mois après la prise de possession du procureur à Saint-Brieuc, trois mois et demi à Tréguier (l'échantillon malouin n'est pas suffisamment étoffé pour permettre ce calcul). Mais certains évêques, comme Le Mintier à Tréguier en 1781, qui séjourne à Rennes pendant les États de Bretagne, peuvent attendre jusqu'à neuf mois avant d'entrer dans leur cité. Il en est de même pour Coëtlogon à Saint-Brieuc en 1683 .

102. Arch. dioc. de Saint-Brieuc, 1 CH 2, délibération capitulaire du 23 octobre 1676. La même formule lapidaire accompagne la prise de possession de Louis-Marcel de Coëtlogon (Id., délibération capitulaire du 20 mars 1683).

103. Ainsi, à la fin de notre période, le chapitre précise clairement que la prise de possession de Gabriel Cortois de Pressigny sera organisée « conformément au Cérémonial romain et aux usages de cette Eglise " (Arch. dép. d’Ille-et-Vilaine, 1 G 268, délibération capitulaire du 6 juin 1786).

104. On peut, en complément, consulter l'étude fouillée de Bertrand Yeurc'h sur les entrées des évêques des neuf évêchés bretons au Moyen Âge. Il en étudie la chronologie, la géographie et les acteurs, identifiant ainsi les similitudes et les différences de cérémoniaux somme toute assez proches. Il conclut son analyse par une présentation accompagnée de commentaires d'un certain nombre de sources. YEURC'H, Bertrand, « Les 
changements comme le montre l'arrivée des prélats aux abords des cités épiscopales. Longtemps, un gentilhomme de haut rang y a accueilli l'évêque avant de le conduire à pied jusqu'au palais épiscopal en tenant la bride de la haquenée sur laquelle il est installé puis de se faire remettre cette dernière. À Tréguier et à Saint-Brieuc, de hauts seigneurs conservent de surcroît la vaisselle dans laquelle l'évêque a bu et mangé. Vraisemblablement sous l'effet de la Réforme catholique ces pratiques jugées démodées et onéreuses sont peu à peu tombées en désuétude, ce qui permet au chanoine briochin Ruffelet de parler au XVIII ${ }^{\mathrm{e}}$ siècle de " cérémonies baroques [...] qui ne s'observent plus depuis longtemps mais qui ont été longtemps à la mode ${ }^{105}$ ". Dès le début du XVII ${ }^{\mathrm{e}}$ siècle, on n'en trouve en effet plus trace à Saint-Brieuc, où le rituel s'est mué en taxe - contestée - due par le nouveau prélat $^{106}$, alors qu'à Saint-Malo on l'observe semble-t-il pour la dernière fois lors de l'entrée de Guillaume Le Gouverneur en $1611^{107}$. Partout, les opérations se déroulent globalement selon le même schéma ${ }^{108}$. Le nouvel évêque fait étape la veille de son entrée à proximité de la cité (sauf à SaintBrieuc) ; il est ensuite accueilli aux portes de la ville par les autorités civiles et le clergé avant de rejoindre le palais épiscopal ou la cathédrale selon les lieux. La journée se termine à la cathédrale, où a lieu la prise de possession personnelle de l'évêché, ou au palais épiscopal. C'est certainement à Tréguier que cette arrivée est la mieux décrite ${ }^{109}$. Les chanoines, en habits, se portent au-devant du nouveau prélat soit à l'église des ursulines soit à celle des hospitalières où ils chantent "l'antienne accoutumée ». De là, la procession rejoint la cathédrale où l'évêque sera successivement conduit

premières entrées épiscopales ", dans YEURC'H, Bertrand, La noblesse en Bretagne. Titres et offices prééminenciers sous les ducs de Bretagne, Perros-Guirec, 2014, p. 101-158.

105. Charles, Olivier (dir.), Christophe-Michel Ruffelet, Les Annales briochines, 1771..., op. cit., p. 347.

106. Sur cette question, se reporter à Ibid., note 599 p. 347-348. Certains évêques comme Ferron de La Ferronnays refusent catégoriquement de verser la somme de 300 livres qui remplace le don de la haquenée : le seigneur du Boisboissel, qui ne renonce pas, se retourne alors contre ses héritiers à son décès (Arch. dép. des Côtes-d'Armor, 1 G 87).

107. Guillotin de CoRson, Amédée, Pouillé historique..., op. cit., p. 623.

108. Qui, incluant évidemment des variantes locales, n’est pas propre à la Bretagne. Les développements suivants doivent beaucoup à GoMIs, Stéphane, "Les entrées solennelles des évêques dans la France des XVII ${ }^{\mathrm{e}}$ et XVIII ${ }^{\mathrm{e}}$ siècles ", dans DompNIER, Bernard (dir.), Les cérémonies extraordinaires du catholicisme baroque, Clermont-Ferrand, Presses universitaire Blaise Pascal, 2009, p. 509-523. Voir également JuLEROT, Véronique, « La première entrée de l'évêque : réflexions sur son origine ", Revue historique, n 639/3, 2006, p. 635-675 et RIVAUD, David, Entrées épiscopales, royales et princières dans les villes du centre-ouest de la France (XIV-XVI s.), Genève, Droz, 2013, 276 p. SAuPIN, Guy, "Les entrées de ville à Nantes au XVII siècle ", Mémoires de la Société d'histoire et d'archéologie de Bretagne, T. LXXI, 1994, p. 153-180 et le dossier "Les entrées royales ", Dix-septième siècle, n²12, 2001 permettent également d'intéressantes comparaisons avec les entrées des souverains qui, alors qu'elles sont fréquentes sous Henri IV et Louis XIII, tombent en désuétude sous Louis XIV.

109. Les récits, plus ou moins détaillés, de huit prises de possession sont insérés dans les délibérations capitulaires. 
dans le chœur - où est chanté un Te Deum en action de grâce pour son arrivée -, au grand autel, à la cathèdre, dans la chambre capitulaire ${ }^{110}$.

Ce cérémonial est animé d'une double logique. D'abord, bien des usages, par ailleurs largement exposés dans le Coeremoniale Episcoporum paru en $1600^{111}$, mettent en scène la primauté de la fonction épiscopale ainsi que l'autorité de seigneur spirituel et temporel du nouveau prélat. À Saint-Malo, il est accompagné au palais puis à la cathédrale non seulement par le clergé mais aussi par les autorités municipales, les représentants de la noblesse locale qui l'ont auparavant accueilli et complimenté ${ }^{112}$, et est même escorté par « la milice bourgeoise sous les armes ${ }^{113}$ ». À Saint-Brieuc, on précise d'ailleurs qu'" il sera fait un port général d'armes des habitants de la ville $^{114}$ ». L'entrée est donc un véritable spectacle visuel qui marque les esprits. Ainsi, à Tréguier, " tout le clergé a commencé la marche en forme de procession, monsieur le chantre avec chape précédé de la croix, du massier et bedeau et avaient ainsi marché jusqu'au palais épiscopal, d'où monseigneur l'évêque revêtu de ses ornements pontificaux assisté de messieurs les archidiacres et trésoriers revêtus de leurs ornements ordinaires, avait été conduit ainsi processionnellement jusqu'à la porte occidentale de cette église ${ }^{115}$ ». À Saint-Brieuc, on n'hésite pas à illuminer la façade de l'hôtel de ville ainsi que celles du palais épiscopal et du séminaire ${ }^{116}$. Mais cette arrivée est aussi un spectacle sonore. L'arrivée de l'évêque de SaintMalo est ainsi saluée par les sonneries des cloches de toute la ville ${ }^{117}$ et par les coups de canons tirés depuis le château et la grande porte, salves qui accompagnent également son confrère briochin ${ }^{118}$. Partout, la traversée de la ville s'effectue au son des cloches et des chants ${ }^{119}$. Il s'agit donc bien « de donner à voir et à entendre dans la ville ${ }^{120}$ " l'entrée du prélat.

110. L'évêque de Tréguier, comme ceux de Saint-Brieuc et Saint-Malo, est chanoine de droit.

111. Sur cet aspect, se reporter à S. GomIs, « Les entrées solennelles des évêques... », loc. cit., p. 521-523 et, plus largement, à DAVY-RigauX, Cécile, DOMPNIER, Bernard, HuREL Daniel Odon (éds.), Les cérémoniaux catholiques en France à l'époque moderne. Une littérature de codification des rites liturgiques, Turnhout, Brepols, 2009, $560 \mathrm{p}$.

112. Pour Saint-Malo, Gullotin DE CoRson, Amédée, Pouillé historique..., op. cit., p. 624; pour Tréguier, par exemple, 2 G 302, délibération capitulaire du 29 mai 1732.

113. Guillotin de Corson, Amédée, Pouillé historique..., op. cit., p. 624.

114. Arch. mun. de Saint-Brieuc, AA 45, extrait des délibérations de la communauté de ville, 20 septembre 1766 .

115. Arch. dép. des Côtes-d'Armor, 2 G 95, délibération capitulaire du 3 janvier 1693.

116. Arch. mun. de Saint-Brieuc, AA 45, extrait des délibérations de la communauté de ville, 20 septembre 1766 .

117. Guillotin de CoRson, Amédée, Pouillé historique..., op. cit., p. 623.

118. Arch. mun. de Saint-Brieuc, AA 45, extrait des délibérations de la communauté de ville, 20 septembre 1766 .

119. Pour Saint-Malo, Gullotin de CoRson, Amédée, Pouillé historique..., op. cit., p. 625; pour Tréguier, par exemple, Arch. dép. des Côtes-d'Armor, 2 G 302, délibération capitulaire du 29 mai 1732.

120. Rivaud, David, Entrées épiscopales, royales et princières..., op. cit., p. 39. 
En même temps, toutes les phases de l'accueil de l'évêque témoignent de la position particulière du chapitre cathédral qui vient d'administrer le diocèse. Ce sont ainsi des chanoines qui escortent l'évêque jusqu'à la ville : à Saint-Malo, deux chanoines vont chercher Gabriel Cortois de Pressigny au séminaire de Saint-Servan ${ }^{121}$; à Saint-Brieuc, " il fut quatre chanoines à Lamballe au-devant de l'évêque ${ }^{122}$ " Denis de La Barde en 1642 et trois pour se porter à la rencontre de Hardouin Fortin de La Hoquette le moment venu en $1676^{123}$; à Tréguier en 1746 , deux chanoines " ont été priés d'aller à Saint-Brieuc ou plus loin au-devant de Mgr notre illustre prélat aussitôt qu'ils apprendront le temps de son arrivée, et de l'accompagner jusqu'en cette ville ${ }^{124} »$. Mais le plus important est ailleurs. C'est en effet le chapitre qui va véritablement introniser l'évêque. À Tréguier, la première étape se déroule devant les portes closes de la cathédrale où le trésorier lui présente le livre des statuts de la compagnie. C'est seulement après avoir promis de " continuer les droits et franchises de cette Église et chapitre et de garder les dits statuts ${ }^{125}$ " qu'il peut pénétrer dans l'église. À Saint-Malo, l'évêque prête les serments sur les Évangiles après avoir été encensé par le président du chapitre. Au préalable, le prélat avait béni l'encens ainsi que les personnes présentes au moyen de l'aspersoir qui lui avait été remis ${ }^{126}$. Les prises de possession livrent quelques éléments relatifs à la liturgie animée par les chanoines. La cérémonie débute par un Te Deum puis l'évêque s'agenouille ou embrasse le maître-autel avant de rejoindre son trône. À Tréguier, le chantre " étant au coin de l'autel à côté de l'épître " entonne alors le verset Protector noster " et autres marqués dans le Pontifical avec l'oraison Deus omnium fidelium pastor ${ }^{127}$ ". À Saint-Malo comme à Tréguier, l'évêque chante ensuite les oraisons en l'honneur des saints locaux, respectivement Malo et Tugdual. Les indications quant à l'accompagnement musical sont rares : à Saint-Malo, le Te Deum est annoncé par le chantre et continué en plain-chant par le chœur, alternativement avec l'orgue ${ }^{128}$. Les cérémonies s'achèvent partout par la bénédiction du nouveau prélat. Ce dernier assiste ensuite à une assemblée capitulaire " avec l'aumusse " au cours de laquelle la compagnie ne manque pas, comme à Saint-Malo en 1786, de lui demander " de vouloir bien l'honorer souvent de sa présence $^{129}$ " : autorité suprême du diocèse, il se voit rappeler avec élégance

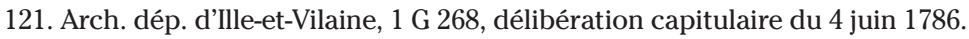

122. Même si le seigneur du Boisboissel vient attendre le nouvel évêque porte SaintGuillaume afin de faire valoir ses droits quelle que soit l'heure de l'arrivée : 17 heures en 1766, 10 heures en 1770, 3 heures en 1775 (Arch. dép. des Côtes-d'Armor, $40 \mathrm{~J}$ 8, procès verbaux de l'entrée de l'évêque dans la cité épiscopale, 1766-1775).

123. Arch. dioc. de Saint-Brieuc, 1 CH 2, délibération capitulaire du 28 septembre 1676.

124. Arch. dép. des Côtes-d'Armor, 2 G 203, délibération du $1^{\mathrm{er}}$ août 1746.

125. Arch. dép. des Côtes-d'Armor, 2 G 302, délibération capitulaire du 29 mai 1732.

126. GullLotin de CoRson, Amédée, Pouillé historique..., op. cit., p. 625.

127. Arch. dép. des Côtes-d'Armor, 2 G 69, délibération capitulaire du 8 août 1767.

128. Guillotin DE CoRson, Amédée, Pouillé historique..., op. cit., p. 626.

129. Arch. dép. d'Ille-et-Vilaine, 1 G 268, délibération capitulaire du 9 juin 1786 . Rappelons que dans nos trois chapitres, l'évêque diocésain jouit des revenus d'une prébende. 
qu'il n'est aussi que l'un des membres - certes particulier - du corps qui assure la continuité de l'institution ecclésiale. Toute l'ambigüité de la relation entre l'évêque et le chapitre semble ainsi résumée. De même, le repas d'accueil du prélat permet au chapitre de rappeler son statut particulier à l'ensemble de la bonne société locale : les chanoines malouins invitent en effet, outre Mgr Gabriel Cortois de Pressigny, « le commandant de la place, le Lieutenant de Roi, M. le comte de Rosnyven conseiller au Parlement au cas qu'il se trouve encore en cette ville; le commandant du Régiment en Garnison à St-Servan, les Commandants du Génie et de l'artillerie, le Sénéchal, le Lieutenant Général de l'amirauté, le Maire de Ville, le commissaire de la Marine, le Directeur des Économats, le Précepteur de cette ville, le Supérieur du Séminaire de St-Servan, le Prieur de Saint-Benoît, le Gardien des Récollets et celui des Capucins ${ }^{130}$ ".

L'entrée des évêques est donc un moment entièrement ritualisé. Le jeu entre les deux acteurs clés - l'un nouveau et de passage; l'autre ancien et permanent - témoigne d'une transmission du pouvoir. La journée revêt donc une dimension contractuelle incontestable et ne témoigne pas d'un simple assujettissement du chapitre à l'évêque. C'est en effet au chapitre que revient l'intronisation du chef du diocèse et ce n'est qu'après sa promesse de respecter les droits du chapitre que la cérémonie peut se déployer et que ce dernier va définitivement repasser au second plan. Ce repli est en réalité amorcé à partir du moment où la nouvelle administration épiscopale est désignée, c'est-à-dire dès la possession par procuration. C'est en effet à cette occasion que sont enregistrées aux insinuations ecclésiastiques les premières lettres de nomination de vicaires généraux accordées par le nouvel évêque. Par ces documents, ce dernier leur délègue sa juridiction volontaire, ou administrative, et contentieuse, ou judiciaire, leur conférant ainsi des pouvoirs étendus ${ }^{131}$.

En général, les nominations se poursuivent pendant quelques mois ${ }^{132}$. À Saint-Malo, Achille de Harlay nomme ainsi André Régnard en février 1632 avant de le remplacer par Louis Morainvilliers d'Orgeville et Jacques Doremet en juin; à Tréguier, les neuf désignations de Jean-Augustin de Frétat de Sarra s'étalent de mars à octobre 1774. La phase de stabilisation peut être encore plus longue : à Saint-Brieuc, Jean-Gabriel de Robien, nommé dès septembre 1766 par François Bareau de Girac est rejoint par René de La Villéon en mai suivant et Thomas L'Ollivier du Tronjoly en octobre, puis par René Louis Le Mintier en mai 1769. On le voit, le nombre de vicaires

130. Arch. dép. d'llle-et-Vilaine, 1 G 268, délibération capitulaire du 30 juin 1785.

131. DuRAND DE MAILlane, Pierre Toussaint, Dictionnaire de droit canonique et de pratique bénéficiale, Lyon, Duplain, 1770, t. IV, p. 662-663. Cela dit, seul l'examen des lettres de vicariat permettra de saisir les attributions précises de chacun tant en terme de missions que d'espace géographique. On sait par exemple qu'à Nancy, La Fare divise son diocèse en districts dont il confie l'administration à ses vicaires généraux (BRYE, Bernard (de) Un évêque de l'Ancien Régime à l'épreuve de la Révolution : le cardinal de La Fare (1752-1829), Paris, Publications de la Sorbonne, 1985, p. 206).

132. Voir annexe 2. 
généraux est inégal selon les diocèses. La photographie de la situation au lendemain des transitions de 1766-1767 dans les trois diocèses le confirme : quatre vicaires sont nommés à Saint-Brieuc, cinq à Saint-Malo et douze à Tréguier. On observe également une tendance à l'augmentation du nombre de vicaires, patente à Saint-Malo et à Tréguier, moins nette à Saint-Brieuc. L'hypothèse consistant à y voir le résultat de deux logiques complémentaires est ici envisageable. La première, locale, le vicaire général étant attaché à l'évêque et révocable à sa convenance ${ }^{133}$, fait de chaque épiscopat un cas particulier, cela même si le nouvel évêque semble reprendre le modèle de son prédécesseur selon une sorte de modèle diocésain. La seconde, générale, est celle de l'accroissement des tâches d'administration, reflet de la bureaucratisation des appareils épiscopaux et/ou des absences plus ou moins fréquentes des prélats.

Les interrogations qui accompagnent certaines nominations, comme à Tréguier où le vicaire général Borie s'étonne auprès de son évêque " que M. l'abbé du Lézart notre grand chantre et $1^{\text {er }}$ dignitaire n'ait pas reçu un mandement de grand vicaire en même temps que votre procuration à prendre possession ${ }^{134}$ ", montrent bien que le vicaire général est avant tout l'homme de l'évêque... qui ne justifie pas son choix. C'est ainsi que se dégage une petite élite diocésaine d'administrateurs de confiance dont le portrait collectif soulève trois questions de fond. Il convient d'abord de se demander si l'accès à la fonction est lié à un type de profil intellectuel, sachant que les évêques ne sont tenus que par une double contrainte : ne nommer que des prêtres gradués ${ }^{135}$. Nos évêques nomment autant de licenciés que de docteurs (21 contre 20) et avant tout des spécialistes de la théologie, spécialité plus adaptée à la fonction que le droit dont la place n'est pour autant pas anecdotique (29 contre 16). Il est d'ailleurs à noter que partout les équipes de vicaires généraux constituées associent le plus souvent théologiens et juristes.

Par ailleurs, le rapport des nouveaux vicaires aux chapitres mérite d'être examiné. Contrairement à une idée certainement trop rapidement reçue, la proportion de chanoines varie fortement selon les lieux : $70 \%$ à Saint-Malo, 57 \% à Saint-Brieuc et $47 \%$ à Tréguier ${ }^{136}$. Les vicaires ne sont donc pas tous, loin s'en faut, issus du vivier capitulaire. Et même si, partout, quelques-uns deviennent chanoines après avoir reçu des lettres de vicaire général, le constat n'épuise pas la question des motifs de leur

133. Le concile de Trente n'impose pas la nomination de vicaires généraux, contrairement à celle d'officiaux.

134. Arch. dép. des Côtes-d'Armor, 1 G 2, correspondance de Mgr Le Mintier (1780-1781), lettre du 17 mai 1780. Yves Marie de Bizien du Lézart est chanoine et chantre depuis 1769. Il a pris possession de l'évêché pour Augustin Le Mintier le 10 mai 1780.

135. Selon l'article 45 de l'ordonnance de Blois de 1554, qui ne précise pas le degré (Durand de Malllane, Pierre Toussaint, Dictionnaire de droit canonique..., op. cit., p. 661). 136. Soit douze sur dix-sept à Saint-Malo, huit sur quatorze à Saint-Brieuc, huit sur dixsept à Tréguier. 
Tableau 3 - La formation des néo-vicaires généraux

\begin{tabular}{|c|c|c|c|c|c|c|c|c|c|}
\hline & \multicolumn{3}{|c|}{ Saint-Brieuc } & \multicolumn{3}{|c|}{ Saint-Malo } & \multicolumn{3}{|c|}{ Tréguier } \\
\hline & 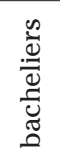 & 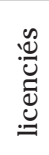 & 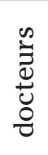 & 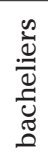 & 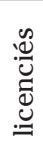 & 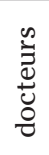 & 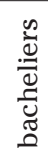 & 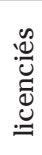 & 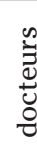 \\
\hline Droit & - & 3 & 1 & - & 6 & - & 2 & 3 & 1 \\
\hline \multirow[t]{2}{*}{ Théologie } & - & 3 & 6 & - & - & 9 & 2 & 5 & 4 \\
\hline & \multicolumn{3}{|c|}{$\begin{array}{c}13 \text { cas documentés } \\
\text { sur } 14\end{array}$} & \multicolumn{3}{|c|}{$\begin{array}{c}15 \text { cas documentés } \\
\text { sur } 17\end{array}$} & \multicolumn{3}{|c|}{$\begin{array}{c}17 \text { cas documenté } \\
\text { sur } 17\end{array}$} \\
\hline
\end{tabular}

choix par les évêques ${ }^{137}$. À défaut d'une proposition de quantification, il est possible de repérer plusieurs logiques. La parenté explique certains choix. Deux évêques de Saint-Malo du début du XvII ${ }^{\mathrm{e}}$ siècle nomment par exemple des neveux : Le Gouverneur nomme Guillaume Blanchard en 1611 et Harlay appelle Louis Morainvilliers d'Orgeville en $1632^{138}$. Des origines communes, derrière lesquelles on peut suspecter l'influence de la fidélité et/ou de la protection, peuvent vraisemblablement éclairer d'autres choix. Par exemple, toujours à Saint-Malo, Claude-Joseph Babin, nommé par Des Laurents en 1767, est originaire de l'évêché d'Avignon comme le prélat. D'ailleurs, il a été pourvu d'une prébende par l'évêque précédent, La Bastie, lui aussi avignonnais. Le prestige spirituel d'un ecclésiastique peut aussi expliquer sa bonne fortune : ainsi de William Gifford, alias Guillaume de Sainte-Marie, à Saint-Malo en $1611^{139}$. Dernière option pour les nouveaux évêques, le choix de l'expérience - de vicaire général et/ou de vicaire capitulaire - semble prévaloir au XVIII ${ }^{\mathrm{e}}$ siècle dans les trois évêchés considérés ${ }^{140}$. En revanche, au sein de notre échantillon de

137. Les remarques suivantes doivent être considérées comme des pistes concernant les raisons des choix des vicaires généraux. Se fondant uniquement sur les vicaires de quelques débuts d'épiscopats, elles n'épuisent évidemment pas le sujet et, surtout, ne permettent pas de hiérarchiser ces motifs à différentes époques. Seules une pesée globale du phénomène vicarial à l'échelle de la province permettra de le faire

138. JouOn DEs LONGRAIS, Frédéric, Jacques Doremet..., op. cit., p. 39 et 49.

139. Ibidem, p. 39-43 et RESTIF, Bruno et Manonmani, "Un Anglais, théologal de Saint-Malo, vicaire général puis archevêque de Reims : Gabriel de Sainte-Marie (1554-1629) ", dans GALLICÉ, Alain, REYDELLET Chantal (textes réunis par), Talabardoneries ou échos d'archives offerts à Catherine Talabardon-Laurent, Rennes, Société d'histoire et d'archéologie de Bretagne, 2011, p. 161-168. Anglais réfugié sur le continent en 1573, il rencontre Charles Borromée à Milan, occupe la fonction de théologal à Rome avant de devenir doyen du chapitre Saint-Pierre de Lille. Un temps recteur de l'université de Reims, il entre chez les bénédictins en 1608 et change de nom. C'est sous Guillaume Le Gouverneur qu'il devient prieur d'une toute nouvelle communauté bénédictine à Saint-Malo et théologal du chapitre.

140. Voir annexe 2 . 
48 néo-vicaires, seul François de Crussoles d'Uzès illustre le portrait de l'épiscopable pour lequel le vicariat fait office de stage professionnel ${ }^{141}$.

Quelles tâches sont dévolues aux vicaires généraux nommés par les nouveaux évêques? La correspondance adressée par Anne Nicolas Borie à Augustin René Louis Le Mintier à Tréguier est à cet égard des plus précieuses $^{142}$. D'abord vicaire capitulaire, Borie confirme à l'évêque qu'après sa prise de possession par procuration du 10 mai 1780, il a " repris l'administration du diocèse en vertu du mandement dont vous m'avez honoré ${ }^{143}$ ". En tant que vicaire général ${ }^{144}$, il s'assure d'abord de la bonne installation de la nouvelle administration puis se propose d'actualiser les documents du secrétariat puisqu'ils doivent porter au plus vite les armes de l'arrivant ${ }^{145}$. Le Mintier diffère sa prise de possession personnelle car, en route pour Tréguier depuis Paris qu'il quitte fin août ou début septembre, il assiste aux États de Bretagne à Rennes où il séjourne dès la mi-septembre 1780 et toujours fin janvier 1781. Il n'entre à Tréguier que le 12 février. Entre les deux prises de possession, Borie administre le diocèse en contact avec son évêque au rythme moyen de cinq lettres par mois, soit une tous les six jours, auxquelles l'évêque répond le plus souvent. Une première approche - nécessairement insuffisante - de cet ensemble documentaire semble montrer que, parmi les multiples questions abordées par le vicaire général, les plus fréquentes portent sur les usages du diocèse, les relations de l'évêque avec les institutions ou les personnalités, l'attitude du chapitre cathédral et des chanoines, des suggestions pour les nominations aux cures, l'affectation des vicaires dans les paroisses, des portraits du personnel diocésain : il rend donc compte à Le Mintier de la vie du diocèse... sans occulter des sujets plus personnels. En toutes choses, Borie s'efforce de maintenir un équilibre entre l'obéissance et l'esprit d'initiative. En effet, d'une part, il applique scrupuleusement les consignes de l'évêque comme, par exemple, lorsqu'il explique avoir instauré " l'aumône de 30 livres pour les ondoiements " suggérée par Le Mintier qui veut en limiter le nombre ${ }^{146}$ mais, d'autre part, il décide, contraint d'agir rapidement, d'affecter l'abbé Le

141. Sur cette question, se reporter à PÉRONnET, Michel, Les évêques de l'ancienne France, Paris, Champion, 1977, volume 1, p. 94. Crussoles est originaire du diocèse de Clermont, abbé commendataire dans celui de Poitiers, vicaire général de Saint-Brieuc à partir de 1728, chanoine à compter de 1730, évêque de Blois de 1734 à 1753 puis de Toulouse jusqu'à 1758 (ChARLEs, Olivier, Chanoines de Bretagne..., op. cit., notice 148, p. 369).

142. Arch. dép. des Côtes-d'Armor, 1 G 2, correspondance de Mgr Le Mintier (1780-1781). Il s'agit d'un riche dossier fort de 45 lettres reçues entre le 26 avril 1780 et le 29 janvier 1781. Une étude approfondie en cours permettra d'étudier au plus près l'activité d'un vicaire général - dans le cadre d'un travail à venir sur le vicariat général en Bretagne et laisse entrevoir la possibilité de dresser un état du diocèse à l'arrivée de Le Mintier.

143. Arch. dép. des Côtes-d'Armor, 1 G 2, lettre du 17 mai 1780.

144. L'évêque lui a fait parvenir sa commission début mai (Arch. dép. des Côtes-d'Armor, 1 G 2 , lettre du 3 mai 1780).

145. Arch. dép. des Côtes-d'Armor, 1 G 2, lettre du 3 mai 1780.

146. Arch. dép. des Côtes-d'Armor, 1 G 2, correspondance de Mgr Le Mintier (1780-1781), lettre du 20 septembre 1780 . 
Bescond auprès de Jean-Hyacinthe Chrestien de Tréveneuc ${ }^{147}$ à Pommerit et de le remplacer « à M. le recteur de Plesidy par M. Parantoen prêtre de la dernière ordination ${ }^{148}$ ". Dans ce cas, bon connaisseur des réalités diocésaines, il explique et justifie sa décision auprès de l'évêque. Par ailleurs, il demande l'avis de ce dernier quant à la marche à suivre pour régler des questions épineuses, comme lorsque l'on découvre "plus de cent brochures à relier des plus détestables " chez Le Roux, marchand libraire à Tréguier $^{149}$. Le vicaire général Borie apparaît donc au travers de cette correspondance comme les yeux et les oreilles mais aussi la voix et le bras de l'évêque absent dans son diocèse ${ }^{150}$.

En définitive, l'examen des périodes interépiscopales des évêchés de Saint-Brieuc, Saint-Malo et Tréguier permet de discerner quelques grands modèles de transition ${ }^{151}$. Quatre d'entre elles se traduiraient par un renouvellement complet des vicaires, c'est-à-dire par une rupture franche avec l'ancienne administration. À l'opposé, onze permettent d'observer la reconduction par le nouvel évêque de personnalités ayant bien souvent été vicaires généraux et vicaires capitulaires. Enfin, à deux reprises semble se dégager un modèle mixte. Cependant, dans bien des cas, il importe d'avoir une vision dynamique de ces moments importants. En effet, des nominations postérieures plus ou moins rapides viennent compléter le dispositif rapproché de l'évêque. S'agit-il pour lui de placer ses créatures, des hommes de confiance, afin de ménager une rupture en douceur une fois que, directement ou par l'intermédiaire des premiers vicaires généraux, le terrain lui est devenu plus familier? On peut légitimement le penser lorsque certains, parfois étrangers au diocèse, sont ensuite placés dans les chapitres cathédraux. Par exemple, le limougeaud Jean-Marc de La Royère fraîchement nommé à Tréguier désigne son compatriote JeanCharles Armand Courtin de Masnaudau comme vicaire général le 8 août

147. Ancien chanoine de la cathédrale de Tréguier (1724-1725), recteur de Pommerit de 1725 à 1783, vicaire général du diocèse de 1725 à 1774 .

148. Arch. dép. des Côtes-d'Armor, 1 G 2, correspondance de Mgr Le Mintier (1780-1781), lettre du 6 octobre 1780 .

149. Arch. dép. des Côtes-d'Armor, 1 G 2, correspondance de Mgr Le Mintier (1780-1781), lettre du 30 octobre 1780. Il s'agit du début de l'affaire Guino - du nom d'un chanoine de la cathédrale, également vicaire général de Lubersac (évêque de 1775 à 1780) puis de Le Mintier, auquel appartiennent les brochures - qui va agiter Tréguier au début des années 1780 (voir DANIEL, René, "La bibliothèque de Jacques-Louis Guino ", Bulletin de la Société archéologique du Finistère, t. 98, 1972, p. 265-296).

150. Ce qui vaut également à la même époque pour Guillaume Floyd de Rosneven, le vicaire général de Quimper en Haute-Cornouaille (JAFFrÉnOU, Andreï, Le clergé de HauteCornouaille à la fin de l'Ancien Régime, mémoire de master 2 (Georges Provost, dir.), université Rennes 2, 2014, t. I, p. 282-286).

151. Il s'agit de comparer les listes des vicaires généraux des anciens évêques, celles des vicaires capitulaires, les premières nominations des nouveaux évêques. À cette fin, il est possible de s'appuyer, rappelons-le, sur dix-sept transitions (voir annexe 2). La typologie proposée se fonde sur la ou les premières nominations opérées par les évêques. 
1767 avant de le pourvoir d'une prébende le 26 octobre $1768^{152}$. À SaintMalo, Achille de Harlay avait placé son neveu Louis de Morainvilliers dans le chapitre cathédral en janvier 1633 après lui avoir confié le vicariat général en juin $1632^{153}$. À Saint-Brieuc, c'est Louis François de Vivet de Montclus qui choisit François de Crussoles d'Uzès comme vicaire en décembre 1728 puis lui octroie une prébende en juillet $1730^{154}$. Mais il peut aussi s'agir de corriger la première initiative en faisant appel au bout de quelque temps à un ecclésiastique expérimenté et efficace : ainsi du rappel de Jacques Doremet à Saint-Malo en février 1612; vraisemblablement de ceux de JeanGabriel de Robien et de René de La Villéon à Saint-Brieuc en mai 1770.

En l'état, l'analyse souffre malheureusement de deux limites : la difficulté à étudier les réalités locales au plus près, d'abord; la moins bonne documentation des périodes reculées ensuite. De ce fait, même s'il faut se garder de projeter sur les périodes les plus anciennes un schéma tardif, il semble bien que les nouveaux évêques ont tendance à accorder à un moment ou à un autre leur confiance à des hommes expérimentés. Faut-il y voir un indice d'un processus sous-jacent, d'un passage d'une logique des liens personnels à celle d'une administration indépendante selon une logique wéberienne ${ }^{155}$, d'une autonomisation progressive du travail de bureau par rapport à la figure de l'évêque? La présence de quelques administrateurs inamovibles, de quelques hommes forts, peut le laisser penser. Ainsi, Louis de Labat de Plaineville meurt à Saint-Brieuc en 1718 " ayant gouverné le diocèse pendant près de 40 ans ${ }^{156}$ " : il aura été vicaire général de Coëtlogon puis de Frétat de Boissieux et vicaire capitulaire entre leurs épiscopats. Son confrère Jean-Baptiste du Plessis de Kersaliou sert quant à lui La Vieuxville, Vivet et Thépault, assurant trois interrègnes et assumant la charge de vicaire général de 1721 à 1749. Il en est de même pour JeanGabriel de Robien, inamovible vicaire entre 1761 et 1790. À Saint-Malo, on retiendra la longévité à la tête du diocèse de Jacques Doremet au service de trois évêques entre 1607 et 1633, de Pierre Henri Nouail de La Contrie également aux côtés de trois prélats sans discontinuer entre 1738 et 1782. Joseph Alexandre Goret de Villepépin apparaît quant à lui à la tête du diocèse au début de la vacance de 1739-1741 entre Desmaretz et La Bastie; il assurera les deux vacances suivantes et sera vicaire général de La Bastie et Des Laurents. Au-delà, cette étude peut-elle être une contribution à celle

152. Voir annexe 2 et Minols, Georges, La Bretagne des prêtres..., op. cit., p. 243.

153. JouOn Des LongraIs, Frédéric, Jacques Doremet..., op. cit., p. 49.

154. Voir supra, note 143.

155. Ce que suggère MEYER, Frédéric, La Maison de l'évêque..., op. cit., p. 495. Il convient cependant d'envisager ce changement dans l'entourage des évêques comme une mutation de longue durée, vraisemblablement inachevée lorsque survient la Révolution. En effet, on ne peut raisonnablement pas y observer dans toute sa pureté l'idéal-type forgé par Max Weber pour qui l'appareil administratif se caractérise par la formation d'un corps de fonctionnaires stables et compétents, des règles régissant des carrières, une hiérarchie claire des responsabilités (se reporter à WEBER, Max, "La domination bureaucratique ", dans La domination. Nouvelle traduction, Paris, La Découverte, 2015, p. 63-118).

156. Arch. dép. des Côtes-d'Armor, 1 G 218, délibération capitulaire du 6 juin 1718. 
de la bureaucratisation du gouvernement des diocèses? au dossier de la naissance de diocèses de papier ${ }^{157}$ ? L'augmentation du nombre de vicaires capitulaires et généraux pourrait militer en ce sens en traduisant une augmentation et/ou une spécialisation des tâches de gestion. Est donc induite la question délaissée pour la Bretagne du travail au quotidien des vicaires, de leurs bureaux, de leur lien avec le terrain - courriers, déplacements, convocations -, le tout en relation avec la vigueur de la mise en œuvre de la Réforme catholique.

Stabilité ou non des administrations? Continuité administrative ou non? Quelle que soit la réponse, il s'agit d'une administration imparfaite dans la mesure où c'est par l'évêque que l'on devient vicaire général, même dans le cas de la reconduction d'une personnalité ayant fait ses preuves : il n'existe en effet pas de structure indépendante avec ses propres procédures de recrutement. Cela étant, en l'état, le dossier conduit à privilégier l'hypothèse d'une certaine stabilité du personnel de direction des diocèses - abordée il est vrai au travers de la seule figure des vicaires capitulaires et des vicaires généraux - au moins en fin de période ${ }^{158}$, quelques exemples semblant par ailleurs montrer, sous réserve d'analyses plus poussées, que la continuité est aussi de mise en ce qui concerne le secrétariat et l'officialité ${ }^{159}$.

157. Tels que les évoque JuLIA, Dominique, " L'administration épiscopale au XVIII ${ }^{\mathrm{e}}$ siècle : de l'inspection des âmes au service public ", dans JouTARD, Philippe (dir.), Histoire de la France religieuse. T. 3. Du roi Très Chrétien à la lä̈cité républicaine (XVIII $-X I X^{e}$ siècle), Paris, Seuil, 1991, p. 369-376 notamment.

158. Cette continuité n'est peut-être pas aussi manifeste partout : ainsi à Vannes, dans la première moitié du XVIII ${ }^{\mathrm{e}}$ siècle lorsque le diocèse est agité par les soubresauts de l'affaire janséniste (MAHUAS, Joseph, Le diocèse de Vannes et le jansénisme, thèse, université de Rennes, 1967, 2 volumes, 622 p.).

159. Je remercie vivement Georges Provost et Bruno Restif qui, après avoir lu une première version de ce texte, ont accepté de me faire bénéficier de leurs remarques et suggestions. 


\section{Annexe 1 - Les évêques de Tréguier, Saint-Brieuc et Saint-Malo (XVI'-XVIII siècle)}

Les données ci-dessous ont été puisées, sauf précision, dans :

- Chapeau, F. Combaluzier, Episcopologe français des temps modernes (1592-1973), Paris, Letouzey et Ané, 1977, 52 p.

- les registres d'insinuations ecclésiastiques et les registres de délibérations capitulaires conservés aux Archives départementales des Côtes-d'Armor pour Tréguier et Saint-Brieuc, aux Archives départementales d'Ille-et-Vilaine pour Saint-Malo.

\section{Références complémentaires}

MinoIs, G., La Bretagne des prêtres dans le Trégor d'Ancien Régime, Spézet, Beltan, 1987, p. 87, 100.

Guillotin de Corson, A., Pouillé historique de l'archevêché de Rennes, Rennes/Paris, Fougeray/Haton, t. I, 1880, p. 597-603.

ReSTIF, B., La Révolution des paroisses. Culture paroissiale et Réforme catholique en Haute-Bretagne aux XVI et XVII siècles, Rennes, PUR, 2006, p. 93.

Jouon DEs Longrais, F., Jacques Doremet, sa vie, ses ouvrages, Rennes, Plihon et Hervé, 1894, p. 34. 


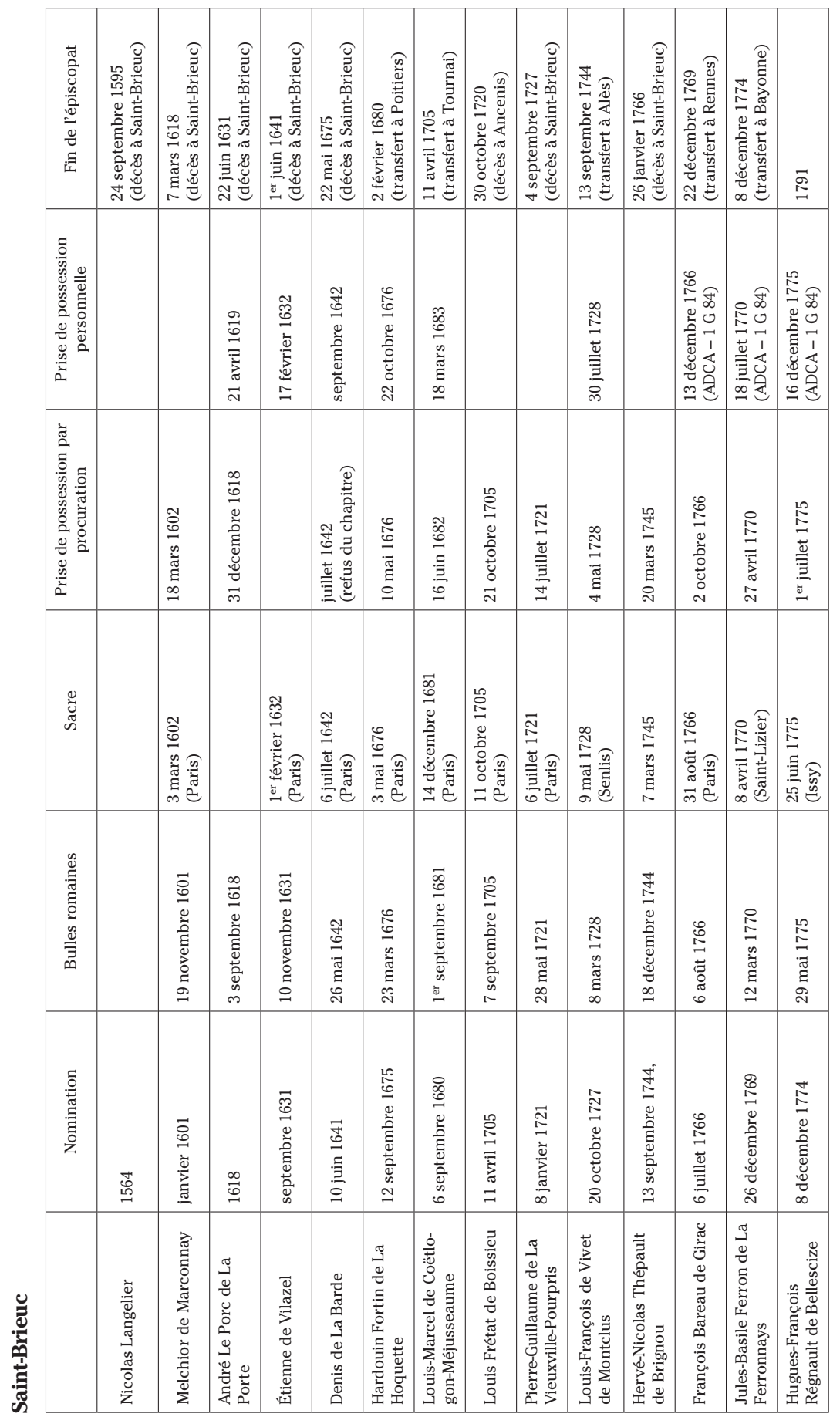




\begin{tabular}{|c|c|c|c|c|c|c|c|c|c|c|}
\hline 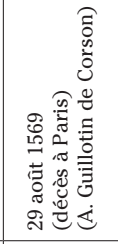 & 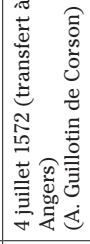 & 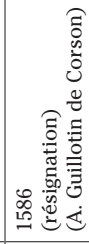 & 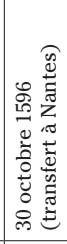 & 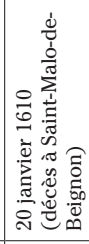 & 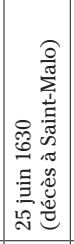 & 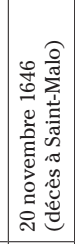 & 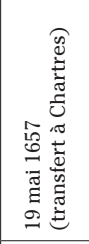 & 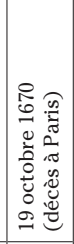 & 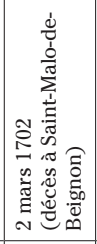 & 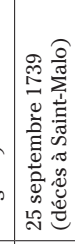 \\
\hline & & 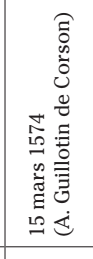 & 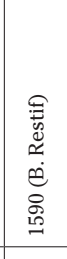 & 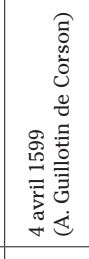 & 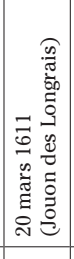 & 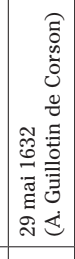 & & & & 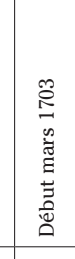 \\
\hline & & & & & 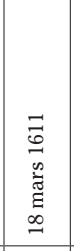 & 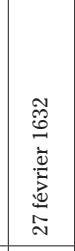 & & 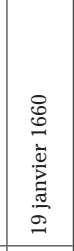 & & 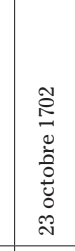 \\
\hline & & 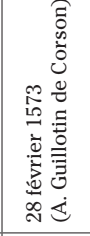 & $\begin{array}{l}\widetilde{\Xi} \\
\tilde{\Xi} \\
\tilde{\varepsilon}\end{array}$ & 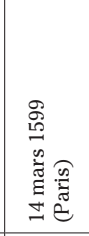 & 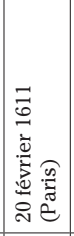 & 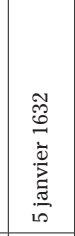 & & 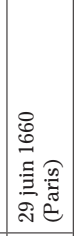 & 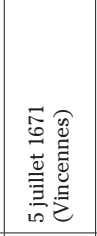 & 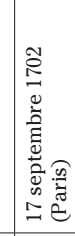 \\
\hline & & 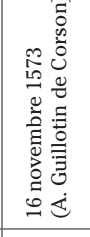 & & 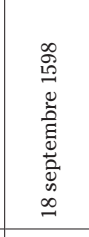 & $\begin{array}{l}\circ \\
0 \\
\stackrel{0}{0} \\
0 \\
0 \\
0 \\
\end{array}$ & 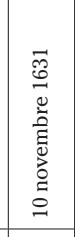 & & 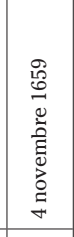 & 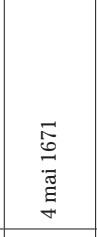 & 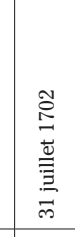 \\
\hline 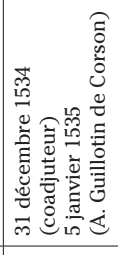 & 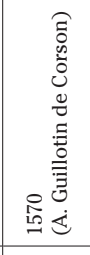 & & 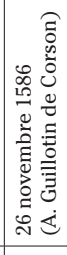 & 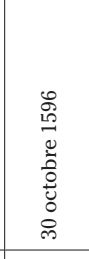 & 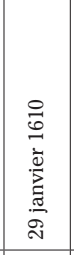 & 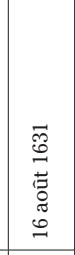 & 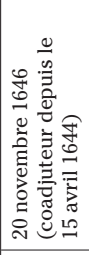 & 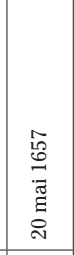 & 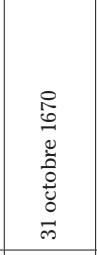 & 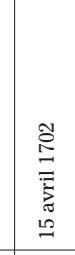 \\
\hline 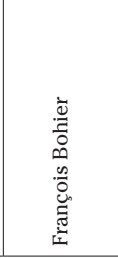 & 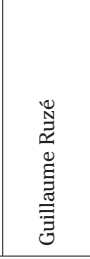 & 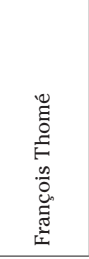 & 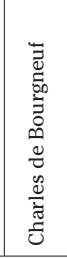 & 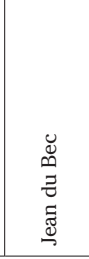 & 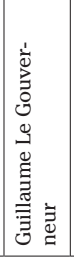 & 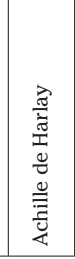 & 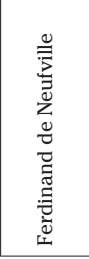 & 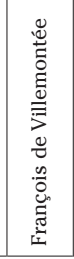 & 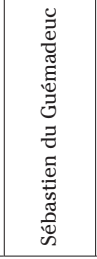 & 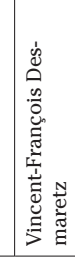 \\
\hline
\end{tabular}



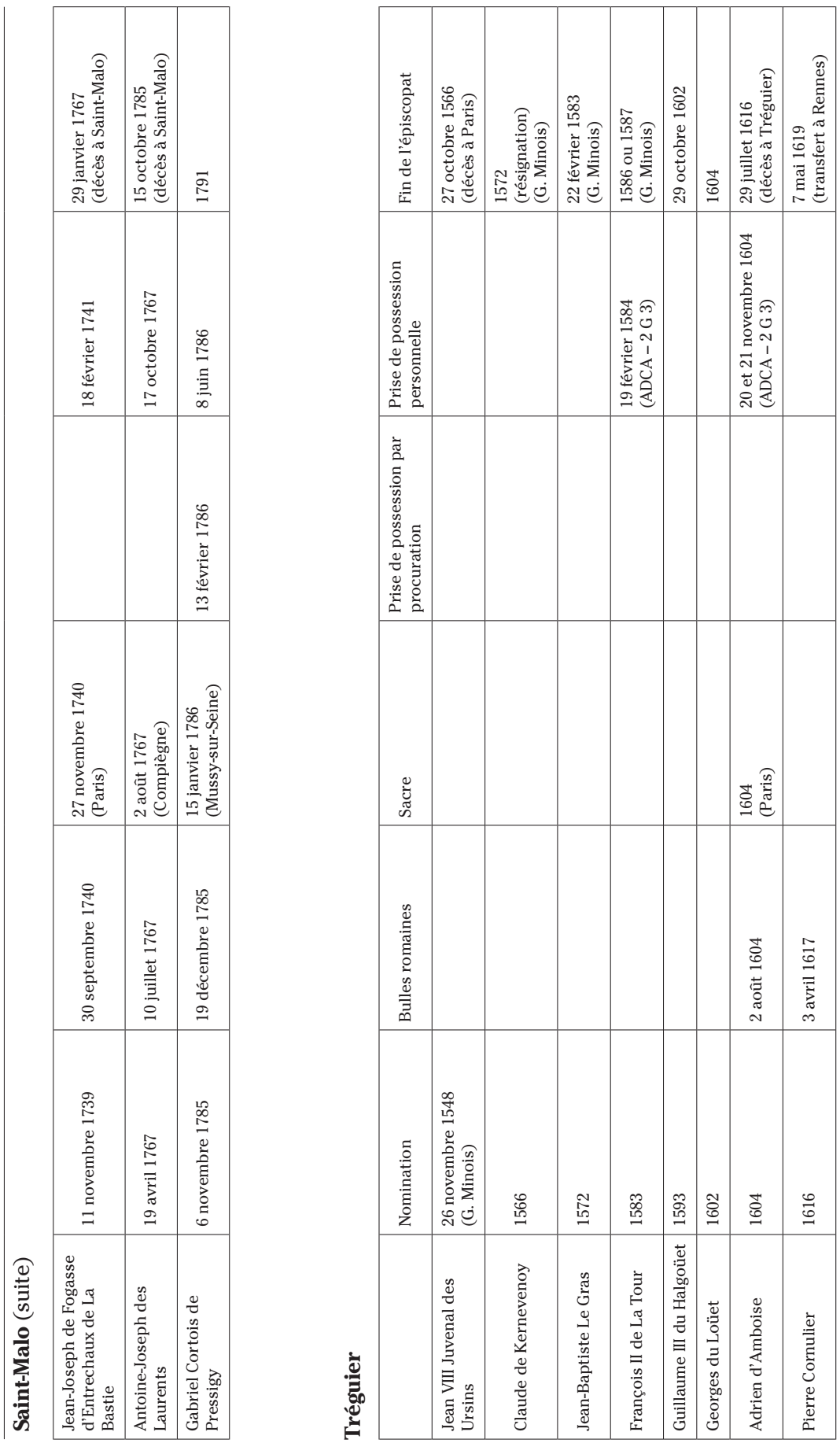


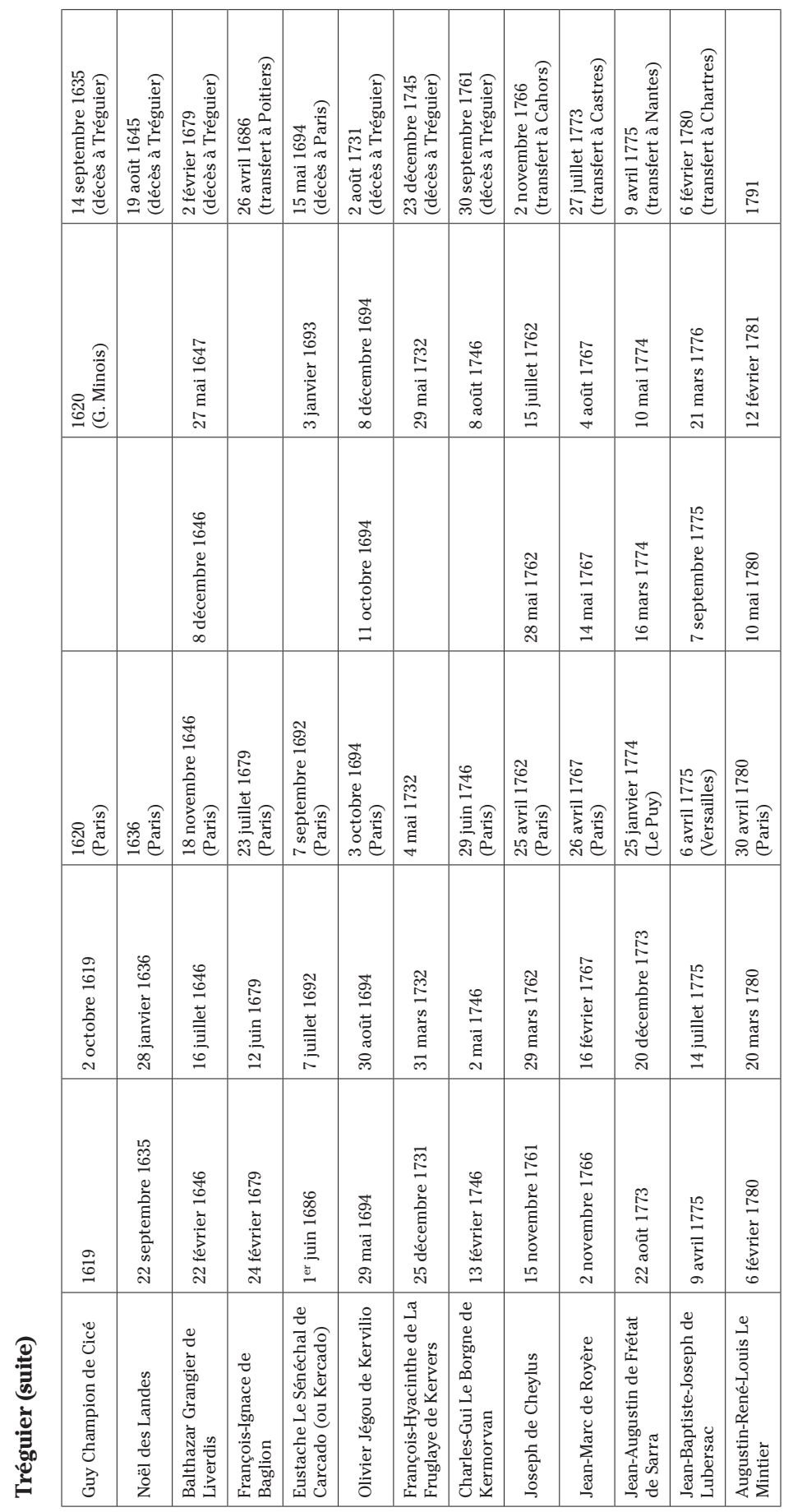




\section{Annexe 2 - Les acteurs des vacances épiscopales}

Les tableaux présentés ci-dessous rassemblent les informations relevées dans les registres de délibérations capitulaires et les registres d'insinuations ecclésiastiques. On y trouve, dans l'idéal, les vicaires généraux (VG) en place lorsque débutent les vacances, la liste des vicaires capitulaires nommés par les chapitres - avec la durée de la vacance et la date de nomination des vicaires entre crochets - et les vicaires généraux désignés par les nouveaux prélats au cours des premiers mois de leurs épiscopats avec l'indication de la date des lettres de vicariat. L'inégale documentation des périodes est liée à la conservation des registres et à l'incommunicabilité de certains documents (pour Tréguier).

\section{1) Saint-Brieuc}

\begin{tabular}{|c|c|c|}
\hline Anciens VG & $\begin{array}{c}\text { Interépiscopat } \\
\text { La Vieuville/Vivet } \\
4 \text { septembre } 1727-4 \text { mai } 1728\end{array}$ & Nouveaux VG \\
\hline $\begin{array}{l}\text { Jean-Baptiste du Plessis de } \\
\text { Kersaliou } \\
\text { André de Ville }\end{array}$ & $\begin{array}{l}\text { [5 septembre 1727] } \\
\text { Jean-Baptiste du Plessis de } \\
\text { Kersaliou } \\
\text { Cyr-Marc-Antoine du Bois de } \\
\text { L'Isle puis Guy-Bonnaventure } \\
\text { de Guersans } \\
\text { Bonnaventure-François Le } \\
\text { Bigot de Neufbourg }\end{array}$ & $\begin{array}{l}\text { Jean-Baptiste du Plessis de } \\
\text { Kersaliou (13/05 } 1728 \text { puis } \\
14 \text { mars } 1729) \\
\text { François de Crussolles d'Uzès } \\
\text { ( } 28 \text { décembre } 1728) \\
\text { Cyr-Marc-Antoine du Bois de } \\
\text { L'Isle(3 mars 1729) } \\
\text { Jacques Du Mans (14 mars } \\
1729)\end{array}$ \\
\hline
\end{tabular}

\begin{tabular}{|l|l|l|}
\hline \multicolumn{1}{|c|}{ Anciens VG } & \multicolumn{1}{|c|}{$\begin{array}{c}\text { Interépiscopat } \\
\text { Vivet/Thépaut (1744-1745) } \\
13 \text { septembre 1744-20 mars } \\
1745\end{array}$} & \multicolumn{1}{|c|}{ Nouveaux VG } \\
\hline $\begin{array}{l}\text { Cyr-Marc-Antoine du Bois } \\
\text { de L'Isle } \\
\text { Jean-Baptiste du Plessis de } \\
\text { Kersaliou }\end{array}$ & $\begin{array}{l}\text { [?] } \\
\text { Jean-Baptiste du Plessis de } \\
\text { Kersaliou } \\
\text { Cyr-Marc-Antoine du Bois } \\
\text { de L'Isle }\end{array}$ & $\begin{array}{l}\text { Cyr-Marc-Antoine du Bois de } \\
\text { L'Isle (20 mars 1745) } \\
\text { Jean-Baptiste du Plessis de } \\
\text { Kersaliou (20 mars 1745) }\end{array}$ \\
& $\begin{array}{l}\text { Jacques Caillet } \\
\text { Florian-François-Célestin du } \\
\text { Merdy de Catuellan }\end{array}$ & \\
\hline
\end{tabular}

\begin{tabular}{|c|c|c|}
\hline Anciens VG & $\begin{array}{c}\text { Interépiscopat } \\
\text { Thépaut/Bareau (1766) } \\
26 \text { janvier 1766-2 octobre } 1766\end{array}$ & Nouveaux VG \\
\hline $\begin{array}{l}\text { Florian-François-Célestin Du } \\
\text { Merdy de Catuellan } \\
\text { Jean-Gabriel de Robien du } \\
\text { Pont-Lô }\end{array}$ & $\begin{array}{l}{[27 \text { janvier } 1766]} \\
\text { Florian-François-Célestin du } \\
\text { Merdy de Catuellan } \\
\text { Jean-Gabriel de Robien du } \\
\text { Pont-Lô } \\
\text { Laurent Chouesmel de La } \\
\text { Salle } \\
\text { René de La Villéon } \\
\text { Mathias-Claude Soubens }\end{array}$ & $\begin{array}{l}\text { Jean-Gabriel de Robien du } \\
\text { Pont-Lô ( } 22 \text { septembre } 1766 \text { ) } \\
\text { René de La Villéon ( } 20 \text { mai } \\
1767) \\
\text { Thomas L'Ollivier du Tronjoly } \\
\text { ( } 29 \text { octobre1767) } \\
\text { René-Louis Le Mintier ( } 7 \text { mai } \\
\text { 1769) }\end{array}$ \\
\hline
\end{tabular}




\begin{tabular}{|c|c|c|}
\hline Anciens VG & $\begin{array}{l}\text { Interépiscopat } \\
\text { Bareau/Ferron } \\
26 \text { février } 1770-10 \text { mai } 1770\end{array}$ & Nouveaux VG \\
\hline $\begin{array}{l}\text { René-Louis Le Mintier } \\
\text { Jean-Gabriel de Robien du Pont-Lô } \\
\text { René de La Villéon } \\
\text { Mathias-Claude Soubens }\end{array}$ & $\begin{array}{l}\text { [26 février } 1770] \\
\text { René-Louis Le Mintier } \\
\text { Jérôme-François de La Nouée } \\
\text { Jean-Gabriel de Robien du Pont-Lô } \\
\text { Mathias-Claude Soubens } \\
\text { René de La Villéon }\end{array}$ & $\begin{array}{l}\text { Charles-Jacques-Denis de Becde- } \\
\text { lièvre }(8 \text { avril } 1770) \\
\text { René de La Villéon (10 mai } 1770) \\
\text { Jean-Gabriel de Robien du Pont-Lô } \\
\text { (10 mai } 1770) \\
\text { Jacques Doyharçabal d'Iturbide } \\
\text { (19 juillet } 1770) \\
\text { Jean-Joseph du Fau ( } 27 \text { juillet } \\
1770)\end{array}$ \\
\hline Anciens VG & $\begin{array}{c}\text { Interépiscopat } \\
\text { Ferron/Bellescize } \\
30 \text { mars } 1775-1^{\text {er }} \text { juillet } 1775\end{array}$ & Nouveaux VG \\
\hline $\begin{array}{l}\text { René de La Villéon } \\
\text { Jean-Gabriel de Robien du } \\
\text { Pont-Lô } \\
\text { Jacques Doyharçabal d'Itur- } \\
\text { bide } \\
\text { Jean-Joseph du Fau }\end{array}$ & $\begin{array}{l}\text { [30 mars 1775] } \\
\text { Jean-Joseph du Fau } \\
\text { Jérôme-François de La Nouée } \\
\text { Mathias-Claude Soubens } \\
\text { René de La Villéon } \\
\text { Jean-Gabriel de Robien du } \\
\text { Pont-Lô } \\
\text { François-Marie Boulard }\end{array}$ & $\begin{array}{l}\text { René de La Villéon }\left(1^{\mathrm{er}} \text { juillet }\right. \\
1775) \\
\text { Jean-Gabriel de Robien du } \\
\text { Pont-Lô }\left(1^{\text {er }} \text { juillet } 1775\right)\end{array}$ \\
\hline
\end{tabular}

\section{2) Saint-Malo}

\begin{tabular}{|c|c|c|}
\hline Anciens VG & $\begin{array}{c}\text { Interépiscopat } \\
\text { du Bec/Le Gouverneur } \\
20 \text { janvier 1610-18 mars } 1611\end{array}$ & Nouveaux VG \\
\hline Jacques Doremet & $\begin{array}{l}{[?]} \\
\text { Jacques Doremet }\end{array}$ & $\begin{array}{l}\text { Guillaume Blanchard ( } 7 \text { mai } \\
\text { 1611) } \\
\text { Guillaume de Gifford alias } \\
\text { Sainte-Marie (fin 1611) } \\
\text { Jacques Doremet (13 février } \\
\text { 1612) }\end{array}$ \\
\hline Anciens VG & $\begin{array}{c}\text { Interépiscopat } \\
\text { Le Gouverneur/Harlay } \\
25 \text { juin } 1630-27 \text { février } 1632\end{array}$ & Nouveaux VG \\
\hline $\begin{array}{l}\text { Jacques Doremet } \\
\text { Guillaume Blanchard }\end{array}$ & $\begin{array}{l}{[?]} \\
\text { Guillaume Blanchard }\end{array}$ & $\begin{array}{l}\text { André Régnard } \\
\text { Louis Morainvilliers d'Orge- } \\
\text { ville ( } 2 \text { juin } 1632) \\
\text { Jacques Doremet ( } 2 \text { juin } 1632 \text { ) }\end{array}$ \\
\hline Anciens VG & $\begin{array}{c}\text { Interépiscopat } \\
\text { Harlay/Neufville } \\
20 \text { novembre } 1646-?\end{array}$ & Nouveaux VG \\
\hline $\begin{array}{l}\text { Louis Morainvilliers d'Orge- } \\
\text { ville }\end{array}$ & $\begin{array}{l}{[?]} \\
\text { Louis Morainvilliers d'Orge- } \\
\text { ville }\end{array}$ & $\begin{array}{l}\text { Louis Morainvilliers d'Orge- } \\
\text { ville }\end{array}$ \\
\hline
\end{tabular}


Les périodes interépiscopales dans les diocèses de Tréguier, Saint-Brieuc et Saint-Malo

\begin{tabular}{|c|c|c|}
\hline Anciens VG & $\begin{array}{c}\text { Interépiscopat } \\
\text { Neufville/Villemontée } \\
7 \text { décembre } 1657-19 \text { janvier } \\
1660\end{array}$ & Nouveaux VG \\
\hline Pierre Berthaud & $\begin{array}{l}\text { [7 décembre 1657] } \\
\text { Guillaume Blanchard } \\
\text { Julien Crosnier }\end{array}$ & $\begin{array}{l}\text { Jacques Symon (31 décembre } \\
\text { 1659) }\end{array}$ \\
\hline Anciens VG & $\begin{array}{c}\text { Interépiscopat } \\
\text { Du Guémadeuc/Desmaretz } \\
2 \text { mars } 1702-23 \text { octobre } 1702\end{array}$ & Nouveaux VG \\
\hline Jean Oréal & [?] & $\begin{array}{c}\text { Jean-Louis Mellet de Mivoys } \\
\text { (17 octobre 1702) } \\
\text { Pierre Eon de La Mettrie } \\
\text { (17 octobre } 1702)\end{array}$ \\
\hline Anciens VG & $\begin{array}{c}\text { Interépiscopat } \\
\text { Desmaretz/La Bastie } \\
25 \text { septembre 1739-18 février } \\
1741\end{array}$ & Nouveaux VG \\
\hline $\begin{array}{l}\text { Henri-Marie Du Breil de } \\
\text { Pontbriand } \\
\text { Pierre-Vital Perrée } \\
\text { Pierre-Henri Nouail de La } \\
\text { Contrie } \\
\text { Louis Clinet de La Chatei- } \\
\text { gneraye } \\
\text { Alain Le Large }\end{array}$ & $\begin{array}{l}{[27 \text { septembre } 1739]} \\
\text { Joseph-Alexandre Goret de } \\
\text { Villepépin }\end{array}$ & $\begin{array}{l}\text { Joseph-Alexandre Goret de } \\
\text { Villepépin (18 février } 1741) \\
\text { Pierre-Henri Nouail de La } \\
\text { Contrie ( } 28 \text { février } 1741)\end{array}$ \\
\hline
\end{tabular}

\begin{tabular}{|l|l|l|}
\hline \multicolumn{1}{|c|}{ Anciens VG } & \multicolumn{1}{|c|}{$\begin{array}{c}\text { Interépiscopat } \\
\text { La Bastie/des Laurents } \\
29 \text { janvier 1767-17 octobre } \\
1767\end{array}$} & \multicolumn{1}{|c|}{ Nouveaux VG } \\
\hline $\begin{array}{l}\text { Pierre-Henri Nouail de La } \\
\text { Contrie }\end{array}$ & $\begin{array}{l}\text { [31 janvier 1767] } \\
\text { Julien Le Bourgeois } \\
\text { Pierre-Henri Nouail de La } \\
\text { Contrie } \\
\text { Joseph-Alexandre Goret de } \\
\text { Villepépin } \\
\text { Antoine-Joseph des Laurents }\end{array}$ & $\begin{array}{l}\text { Joseph-Alexandre Goret de } \\
\text { Villepépin (17 octobre 1767) } \\
\text { Pierre-Henri Nouail de La } \\
\text { Contrie(17 octobre 1767) } \\
\text { Julien Le Bourgeois (17 oc- } \\
\text { tobre 1767) } \\
\text { Claude-Joseph-Marie } \\
\text { Babin(17 octobre 1767) } \\
\text { René Du Breil de Pontbriand } \\
\text { de La Caunelais (10 novembre } \\
1767)\end{array}$ \\
\hline
\end{tabular}




\begin{tabular}{|c|c|c|}
\hline Anciens VG & $\begin{array}{l}\text { Interépiscopat } \\
\text { des Laurents/Cortois } \\
15 \text { octobre } 1785 \text {-13 février } \\
1786\end{array}$ & Nouveaux VG \\
\hline $\begin{array}{l}\text { Gilles-Nicolas Durand de La } \\
\text { Furonnière } \\
\text { Alexandre-Basile Rozy } \\
\text { François-Marie-Toussaint Du } \\
\text { Fresne des Saudrais }\end{array}$ & $\begin{array}{l}\text { [16 octobre 1785] } \\
\text { Joseph-Alexandre Goret de } \\
\text { Villepépin } \\
\text { Jacques-Julien Meslé de } \\
\text { Grandclos } \\
\text { Etienne-Jérôme Croupier de } \\
\text { Keraudran } \\
\text { Pierre-Nicolas Rousselin Du } \\
\text { Rocher } \\
\text { Gilles-Nicolas Durand de La } \\
\text { Furonnière } \\
\text { Alexandre-Basile Rozy } \\
\text { François-Marie-Toussaint Du } \\
\text { Fresne des Saudrais }\end{array}$ & $\begin{array}{l}\text { François-Marie-Toussaint } \\
\text { Du Fresne des Saudrais } \\
\text { (13 février 1786) } \\
\text { Alexandre-Basile Rozy } \\
\text { (13 février 1786) } \\
\text { Gilles-Nicolas Durand de La } \\
\text { Furonnière (13 février 1786) } \\
\text { Jacques-Julien Meslé de } \\
\text { Grandclos (13 février 1786) }\end{array}$ \\
\hline
\end{tabular}

\section{3) Tréguier}

\begin{tabular}{|c|c|c|}
\hline Anciens VG & $\begin{array}{c}\text { Interépiscopat } \\
\text { Champion/Deslandes } \\
14 \text { septembre 1635-? }\end{array}$ & Nouveaux VG \\
\hline & $\begin{array}{l}\text { [15 septembre 1635] } \\
\text { René de Rosmar } \\
\text { Guillaume André }\end{array}$ & \\
\hline \multirow[t]{2}{*}{ Anciens VG } & $\begin{array}{c}\text { Interépiscopat } \\
\text { Deslandes/Grangier } \\
19 \text { août } 1645-8 \text { octobre } 1646\end{array}$ & Nouveaux VG \\
\hline & $\begin{array}{l}\text { [21 août } 1645] \\
\text { René de Rosmar } \\
\text { Pierre Fanoys }\end{array}$ & \\
\hline Anciens VG & $\begin{array}{c}\text { Interépiscopat } \\
\text { Le Sénéchal/Jégou } \\
15 \text { mai } 1694-11 \text { octobre } 1694\end{array}$ & Nouveaux VG \\
\hline Michel Sevin & $\begin{array}{l}\text { [ } 21 \text { mai } 1694 \text { ] } \\
\text { Marc-Antoine Deslandes } \\
\text { Michel Sevin } \\
\text { Mathurin Fournier }\end{array}$ & $\begin{array}{l}\text { Michel Sevin (mentions à } \\
\text { partir du } 4 \text { septembre } 1694 \text {; } \\
\text { lettre le } 15 \text { août } 1695 \text { ) } \\
\text { Mathurin Fournier (mentions } \\
\text { à partir du } 4 / 091694 \text {; lettre le } \\
15 \text { août } 1695 \text { ) } \\
\text { Marc-Antoine Deslandes } \\
\text { (mentions à partir du } 4 / 09 \\
1694 \text {; jusque début } 1695 \text { ) }\end{array}$ \\
\hline
\end{tabular}


Les périodes interépiscopales dans les diocèses de Tréguier, Saint-Brieuc et Saint-Malo

\begin{tabular}{|c|c|c|}
\hline Anciens VG & $\begin{array}{c}\text { Interépiscopat } \\
\text { Jégou/La Fruglais } \\
2 \text { août } 1731-29 \text { mai } 1732\end{array}$ & Nouveaux VG \\
\hline & $\begin{array}{l}\text { [6 août } 1731] \\
\text { Jean-Jacques de Bizien du } \\
\text { Lézart } \\
\text { Philibert Le Gendre } \\
\text { Jean-Hyacinthe Chrestien de } \\
\text { Tréveneuc }\end{array}$ & \\
\hline
\end{tabular}

\begin{tabular}{|c|c|c|}
\hline Anciens VG & $\begin{array}{c}\text { Interépiscopat } \\
\text { La Fruglais/Le Borgne } \\
23 \text { décembre } 1745-2,3 \text { ou } \\
4 \text { août } 1746\end{array}$ & Nouveaux VG \\
\hline & $\begin{array}{l}\text { [24 décembre 1745] } \\
\text { Louis-Marie-Hypolithe de } \\
\text { Bizien du Lézart } \\
\text { Yves de Calloët de Lanidy } \\
\text { François-Gabriel de Kérouzy } \\
\text { Philibert Le Gendre }\end{array}$ & \\
\hline
\end{tabular}

\begin{tabular}{|l|l|l|}
\hline Anciens VG & \multicolumn{1}{|c|}{$\begin{array}{c}\text { Interépiscopat } \\
\text { Le Borgne/Cheylus } \\
30 \text { septembre 1761-? }\end{array}$} & Nouveaux VG \\
\hline & {$[?]$} & \\
& Louis-Marie-Hypolithe de & \\
Bizien du Lézart & \\
& Claude-Charles de Perrien & \\
& Eléonore-Marie Le Gendre de & \\
& Villorbaine & \\
\hline
\end{tabular}

\begin{tabular}{|c|c|c|}
\hline Anciens VG & $\begin{array}{c}\text { Interépiscopat } \\
\text { Cheylus/La Royère } \\
15 \text { janvier 1767-14 mai } 1767\end{array}$ & Nouveaux VG \\
\hline $\begin{array}{l}\text { Claude-Charles de Perrien } \\
\text { Jean-François de La Marche } \\
\text { Fidèle-François-Suzanne Le } \\
\text { Mercier de Montigny }\end{array}$ & $\begin{array}{l}\text { [15 janvier 1767] } \\
\text { Louis-Emmanuel de Bizien } \\
\text { du Lézart } \\
\text { Claude-Charles de Perrien } \\
\text { Jean-François de La Marche } \\
\text { Anne-Nicolas Borie } \\
\text { Fidèle-François-Suzanne Le } \\
\text { Mercier de Montigny }\end{array}$ & $\begin{array}{l}\text { Claude-Charles de Perrien } \\
\text { (15 mai 1767) } \\
\text { Anne-Nicolas Borie (15 mai } \\
\text { 1767) } \\
\text { Laurent-Charles du Breil de } \\
\text { Rays ( } 22 \text { mai } 1767) \\
\text { Louis-Emmanuel de Bizien du } \\
\left.\text { Lézart ( } 1^{\text {er }} \text { mai } 1767\right) \\
\text { Philibert-Claude Chiquet de } \\
\text { Fontenaye (? juillet } 1767) \\
\text { Jean-Hyacinthe Chrestien de } \\
\text { Tréveneuc ( } 4 \text { août } 1767) \\
\text { Jean-Charles-Armand Coustin } \\
\text { de Masnadau ( } 8 \text { août } 1767) \\
\text { Joseph-Mathurin Le Mintier } \\
\text { (29 août } 1767) \\
\text { Pierre-Claude du Crot (14 juil- } \\
\text { let } 1768 \text { ) } \\
\text { Laurent-Marie Bouden de Tro- } \\
\text { melin ( } 29 \text { septembre } 1768) \\
\text { Sébastien-Corentin Le Dall de } \\
\text { Tromelin (4 octobre } 1768 \text { ) } \\
\text { Yves-Marie de Bizien du } \\
\text { Lézart (26 novembre } 1768 \text { ) }\end{array}$ \\
\hline
\end{tabular}




\section{Olivier CHARLES}

\begin{tabular}{|c|c|c|}
\hline Anciens VG & $\begin{array}{c}\text { Interépiscopat } \\
\text { La Royère/Sarra } \\
1^{\mathrm{er}} \text { octobre } 1773-16 \text { mars } 1774\end{array}$ & Nouveaux VG \\
\hline $\begin{array}{l}\text { Sébastien-Corentin Le Dall de } \\
\text { Tromelin } \\
\text { Yves-Marie de Bizien du } \\
\text { Lézart } \\
\text { Toussaint-Joseph-Pierre du } \\
\text { Boisboissel } \\
\text { Jean-Charles-Armand Coustin } \\
\text { de Masnadau } \\
\text { Anne-Nicolas Borie }\end{array}$ & $\begin{array}{l}\text { [6 octobre 1773] } \\
\text { Yves-Marie de Bizien du } \\
\text { Lézart } \\
\text { Jean-Charles-Armand Coustin } \\
\text { de Masnadau } \\
\text { Anne-Nicolas Borie } \\
\text { Jacques-Joseph de Montau- } \\
\text { douin } \\
\text { Sébastien-Corentin Le Dall de } \\
\text { Tromelin } \\
\text { Toussaint-Joseph-Pierre du } \\
\text { Boisboissel }\end{array}$ & $\begin{array}{l}\text { Yves-Marie de Bizien du } \\
\text { Lézart (16 mars 1774) } \\
\text { Anne-Nicolas Borie (16 mars } \\
1774) \\
\text { Claude-Charles de Perrien } \\
\text { (12 mai 1774) } \\
\text { Jean-Hyacinthe Chrestien de } \\
\text { Tréveneuc (12 mai } 1774) \\
\text { Laurent-Marie Bouden de } \\
\text { Tromelin ( } 22 \text { mai } 1774) \\
\text { Antoine-Joseph de Boissieu } \\
\text { de Servière (20 juin } 1774) \\
\text { Toussaint-Joseph-Pierre du } \\
\text { Boisboissel (10 octobre } 1774) \\
\text { Jean-Charles-Armand Coustin } \\
\text { de Masnadau } \\
\text { (10/10 1774) } \\
\text { Sébastien-Corentin Le Dall de } \\
\text { Tromelin (24 octobre 1774) }\end{array}$ \\
\hline
\end{tabular}


Les périodes interépiscopales dans les diocèses de Tréguier, Saint-Brieuc et Saint-Malo

Annexe 3 - Les procureurs des évêques de Saint-Brieuc

\begin{tabular}{|c|c|c|}
\hline Évêques & Procureurs & Qualités des procureurs \\
\hline $\begin{array}{l}\text { Melchior de Marconnay } \\
(1602)\end{array}$ & Pierre Demay & Prêtre du diocèse d'Amiens \\
\hline $\begin{array}{l}\text { André Le Porc de La } \\
\text { Porte (1618) }\end{array}$ & Jean Charpentier & Prêtre, doyen du chapitre, chanoine \\
\hline $\begin{array}{l}\text { Hardouin Fortin de La } \\
\text { Hoquette (1676) }\end{array}$ & $\begin{array}{l}\text { François Lestic de } \\
\text { Vaudurand }\end{array}$ & $\begin{array}{l}\text { Prêtre, chanoine de la collégiale Saint-Guil- } \\
\text { laume de Saint-Brieuc }\end{array}$ \\
\hline \multirow{2}{*}{$\begin{array}{l}\text { Louis-Marcel de Coëtlo- } \\
\text { gon (1682) }\end{array}$} & $\begin{array}{l}\text { Pierre-Jean Le } \\
\text { Chapelier }\end{array}$ & $\begin{array}{l}\text { Prêtre, docteur de Sorbonne, scolastique du } \\
\text { chapitre, chanoine }\end{array}$ \\
\hline & $\begin{array}{l}\text { Michel Le Breton } \\
\text { du Pré }\end{array}$ & Prêtre, docteur de Sorbonne, chanoine \\
\hline $\begin{array}{l}\text { Louis Frétat de Boissieu } \\
(1705)\end{array}$ & $\begin{array}{l}\text { Louis de Labat de } \\
\text { Plaineville }\end{array}$ & $\begin{array}{l}\text { Prêtre, archidiacre du chapitre, vicaire général } \\
\text { de Coëtlogon, vicaire capitulaire }\end{array}$ \\
\hline $\begin{array}{l}\text { Pierre-Guillaume de } \\
\text { La Vieuxville-Pourpris } \\
(1721)\end{array}$ & André de Ville & $\begin{array}{l}\text { Prêtre, docteur en théologie, archidiacre du } \\
\text { chapitre, vicaire général de Frétat de Boissieu }\end{array}$ \\
\hline $\begin{array}{l}\text { Louis-François de Vivet } \\
\text { de Montclus (1728) }\end{array}$ & $\begin{array}{l}\text { Jean-Baptiste du } \\
\text { Plessis de Kersa- } \\
\text { liou }\end{array}$ & $\begin{array}{l}\text { Prêtre, docteur en droit canon et civil, doyen } \\
\text { du chapitre, chanoine, vicaire général de La } \\
\text { Vieuxville, vicaire capitulaire }\end{array}$ \\
\hline $\begin{array}{l}\text { Hervé-Nicolas Thépault } \\
\text { du Breignou (1745) }\end{array}$ & $\begin{array}{l}\text { Jean-Baptiste du } \\
\text { Plessis de Kersa- } \\
\text { liou }\end{array}$ & $\begin{array}{l}\text { Prêtre, docteur en droit canon et civil, doyen } \\
\text { du chapitre, chanoine, vicaire général de Vivet } \\
\text { de Montclus, vicaire capitulaire }\end{array}$ \\
\hline $\begin{array}{l}\text { François Bareau de Girac } \\
(1766)\end{array}$ & $\begin{array}{l}\text { Florian-François- } \\
\text { Célestin du Merdy } \\
\text { de Catuélan }\end{array}$ & $\begin{array}{l}\text { Prêtre, licencié « in utroque jure ", doyen du } \\
\text { chapitre, chanoine, vicaire général de Thépault } \\
\text { du Breignou, vicaire capitulaire }\end{array}$ \\
\hline $\begin{array}{l}\text { Jules-Basile Ferron de La } \\
\text { Ferronnays (1770) }\end{array}$ & $\begin{array}{l}\text { Charles-Jacques- } \\
\text { Denis de Becde- } \\
\text { lièvre }\end{array}$ & $\begin{array}{l}\text { Prêtre, licencié en théologie, chanoine, vicaire } \\
\text { général de Bareau de Girac }\end{array}$ \\
\hline $\begin{array}{l}\text { Hugues-François } \\
\text { Régnault de Bellescize } \\
\text { (1775) }\end{array}$ & René de La Villéon & $\begin{array}{l}\text { Prêtre, docteur de Sorbonne, trésorier du } \\
\text { chapitre, chanoine, vicaire général de Ferron } \\
\text { de La Ferronnays, vicaire capitulaire }\end{array}$ \\
\hline
\end{tabular}




\section{RÉSUMÉ}

L'entourage proche des évêques bretons d'Ancien Régime n'a guère été étudié. Les périodes de transition entre deux épiscopats sont en la matière des postes d'observation privilégiés pour amorcer une étude des administrations épiscopales et de leur personnel. Leur examen permet de mettre en lumière les stratégies des nouveaux évêques à l'égard des personnages clés que sont les vicaires généraux, d'autant qu'ils doivent composer avec un autre acteur de poids, les chapitres cathédraux qui réaffirment leur position en administrant temporairement le diocèse par l'intermédiaire de vicaires capitulaires. L'examen des interrègnes des diocèses de Tréguier, Saint-Brieuc et Saint-Malo entre la Ligue et la Révolution semble montrer que la confiance accordée à des personnalités expérimentées s'impose progressivement au détriment de la nomination de fidèles. Ce sont ainsi les prémices de la mise en place de véritables administrations qui sont dévoilées.

\section{ABSTRACT}

The close entourage the Breton bishops of the Ancient Regime has hardly ever been studied. The periods of transition which occurred between two episcopacies provide a highly privileged vantage point from which to commence a study of episcopal administrations and of the personnel of which they were composed. Close study of these transition periods allows us to shed light upon the strategies of the new bishops and their dealings with key staff (i.e. the Vicars General), who had to deal with the formidable Cathedral (diocesan) chapter, which, for its part, was reaffirming its own position by temporarily taking charge of the diocese via the vicars capitular. Through examination of the interregnums of the dioceses of Tréguier, Saint Brieuc and Saint Malo, during the period between the Wars of the Catholic League and the French Revolution, it seems that when it came to appointing staff, experience was gradually favoured over mere loyalty. These are the first signs of a gradual move towards the creation of the model of administration in France that we know today. 